\title{
Guidelines for the Management of Severe Head Injury, 2nd Edition Guidelines from the Guidelines Committee on the Management of Severe Head Injury, the Japan Society of Neurotraumatology
}

The guidelines are officially approved by the Japan Neurosurgical Society

Members of the Guidelines Committee on the Management of Severe Head Injury contributed to the 2nd Japanese version:

Chairman Minoru SHIGEMORI

Members Toshiaki ABE, Tohru ARUga, Takeki OgawA, Hiroshi OKUderA, Junichi ONO, Takehide ONUMA, Yoichi KATAYAMA, Nobuyuki KAWAI, Tatsuro KAWAMATA, Eiji KOHMURA, Toshisuke SAKAKI, Tetsuya SAKAMOTO, Tatsuya SASAKI, Akira SAto, Toshiyuki ShiOgaI, Katsuji Shima, Kazuo SugiUra, Yoshio TAKASATO, Takashi TOKUTOMI, Hiroki TOMITA, Izumi TOYODA, Seigo NAGAO, Hiroshi NAKAMURA, Young-soo PARK, Mitsunori MATSUMAE, Tamotsu MIKI, Yasushi MIYAKE, Hisayuki MURAI, Shigeyuki MURAKAMI, Akira YAMAURA, Tarumi YAMAKI, Kazuo YAMADA, and Toshiki YOSHIMINE

\section{Foreword}

In 1998, the Guidelines Committee on the Management of Severe Head Injury was established by the Japan Society of Neurotraumatology, and performed a critical review of national and international studies published over the past 10 years. The guidelines were first published in 2000 based on the results of this literature review and the Committee consensus, and the 2nd revised edition was published in 2006. This English version of the 2nd edition of the guidelines is intended to promote its concepts and use worldwide.

Key words: head injury, traumatic brain injury, neurotrauma, guidelines, management

\section{INTRODUCTION}

On the Revision (2nd Edition) of the Guidelines for the Treatment and Management of Severe Head Injuries

The Guidelines for the Treatment and Management of Severe Head Injuries (1st edition) were published in 2000. Prior to this, there had been various controversies over the significance of creating guidelines, but the basic consensus considered that maintaining the "quality of medical care" constantly at an appropriate level (standardization of diagnosis, treatment, and management) is the most important

Address to which opinions and comments should be directed: Secretariat of the Japan Society of Neurotraumatology, c/o Department of Neurosurgery, The Jikei University School of Medicine, 3-25-8 Nishi-Shinbashi, Minato-ku, Tokyo 105-8461, Japan. TEL: +81-3-3433-1111; FAX: + 81-3-3459-6412; E-mail: neurotrauma@jikei.ac.jp. 
for patients and the general public, so the guidelines were prepared following this concept. Today, 6 years after the publication of the 1st edition, the importance of guidelines has become even greater.

Here, the "quality of medical care" is based on the concept of quality in the broader sense of the meaning, including the viewpoint of "efficiency" related to the medical resources to be used and the "patients' safety and sense of security." That is in addition to the "net quality," which is the quality in the narrower sense of the meaning, represented by the therapeutic results. Ultimately, as high-quality medical care is "the desirable state of medical care," Guidelines for the Treatment and Management of Severe Head Injuries must also be prepared in search of the "desirable state of medical care."

Concerning the "standardization" proposed by the Guidelines for the Treatment and Management of Severe Head Injuries, Advanced Cardiovascular Life Support and Japan Advanced Trauma Evaluation and Care (JATEC) have already been issued by the related scientific associations. At individual facilities, the use of a "clinical path" is increasing. The clinical path is considered to be a hypothesis concerning the "best management of the patient" jointly prepared by an individual management team. While a clinical path may lack evidence, it is considered to allow the implementation of a standard course of treatment. For example, even in a management scenario participated in by many residents, a clinical path ensures implementation of the diagnosis and treatment at a certain level and standard. The new edition of the Guidelines also aims to be part of such attempt to standardize.

The Japan Society of Neurotraumatology has conducted the activities of the Japan Neurotrauma Data Bank (JNTDB) with the cooperation of the Japanese Council of Traffic Science. Evaluation of the results of data analysis is considered to be useful for the transition of these guidelines to more evidencebased ones. Furthermore, clinical indicators (CIs) concerning the treatment and management of severe head injuries may be developed in the near future. We hope that guidelines based on CIs and evidence will be prepared and disseminated in a manner living up to public expectations. This revision has been made with the understanding of this historical process. We hope that these revised guidelines will be used widely for the standardization of the treatment and management of severe head injuries, particularly with the objective of identifying the minimum essentials and actions to be avoided.

The fundamental spirit of the publication of this edition and its use are the same as those described in the introduction to the 1st edition. We welcome opinions and comments on these guidelines that will promote further development and wider acceptance.

September, 2006

\section{Introduction to the 1st Edition}

\section{About severe head injuries in Japan}

According to the demographics (Ministry of Health, Labour and Welfare) in 1997, the most frequent cause of death in the population aged 1-24 years is "accidents," which also remains among the top 3 causes of death in those aged 25-39 years. Moreover, about half of the deaths caused by accidents are due to head injuries. Since 2-10 times more the number of those who died suffer serious physical, neurological, or psychological damage, even if they escaped death (Japan Neurotrauma Databank, Traumatic Coma Databank [USA], and Teasdale GM [International Conference on Recent Advances in Neurotraumatology in 1999]), head injuries are considered to inflict immeasurable damage to society.

Formerly, there was pessimism over the treatment of parenchymal injuries of the brain, but recent laboratory and clinical studies on head injuries have shown that hypoxia and hypotension immediately after injury greatly affect secondary damage. This means that the outcome may differ widely depending on the treatment or management early after injury. On the basis of this observation, guidelines concerning the treatment or management of severe head injuries have recently been issued in Western countries, and the therapeutic results and outcomes are expected to improve by conducting standardized treatment. These guidelines are also expected to indicate directions for improvement in medical education and the development of new methods of treatment and management, as well as to eliminate the unnecessary ones, reducing medical costs. In Japan, however, there is marked regional variation in facilities that can treat patients with severe head injuries under the medical insurance schema and the clinical system is completely different from those in Western countries. Therefore, it is considered extremely difficult to apply directly Western guidelines, and creating consensus concerning the treatment and management of severe head injuries in Japan might be difficult. Under these circumstances, the preparation of guidelines for more universal and effective treatment and management by analyzing the present status and incorporating the results of clinical studies and expert opinions in Japan is considered to be of major significance. 


\section{Target patients}

Severe head injuries primarily dealt with in these guidelines are closed head injuries in adults with a Glasgow Coma Scale (GCS) score of 8 or less after resuscitation (Note; GCS scores $\leq 8$ are considered to correspond to Japan Coma Scale [JCS] scores $\geq 30$ ). Patients in whom the GCS score after resuscitation is 9 or above but deteriorate to 8 or less after admission due to secondary brain damage are also included. Concerning children and elderly patients, only those points of management that are supported with references at present are mentioned. Multiple head injuries and head injuries complicated by spinal cord injury were excluded from this edition, because these conditions are more complex and need different approaches from simple head injuries.

\section{On using these guidelines}

These guidelines were prepared to serve academic purposes and for use by primary care physicians dealing with severe head injuries such as neurosurgeons and emergency care physicians. These guidelines were also meant to be easy to understand by physicians in general, nurses, allied health professionals and paramedics such as emergency medical technicians.

In addition to first aid before arrival at the hospital, resuscitation and management in the intensive care unit (ICU), many items including indications to surgical treatment and analysis of the present status of special treatment methods, such as barbiturate therapy and hypothermia, were evaluated. According to similar guidelines in the USA, only 3 of these statements were supported by clear and sufficient scientific evidence. They were the following: 1) Prolonged hyperventilation should be avoided in patients with a normal intracranial pressure (ICP); 2) Glucocorticoid administration provides no benefit to patients with head injuries; and 3) Administration of phenytoin, carbamazepine, or phenobarbital is expected to have no inhibitory effect on the occurrence of late epilepsy. These and other items should be taken as experts' recommendations. Therefore, we hope that users of these guidelines do not unconditionally follow them in managing severe head injuries, always remembering that many issues remain unresolved, and that new scientific results continue to contribute to future progress in medicine.

Also, the guidelines may be used as a reference on making decisions in medical controversies and lawsuits, but as the best treatment changes day by day, whether each item of the guidelines should be followed is left to the decision of individual physicians, and they are not intended to restrict rigidly the medical actions that have to be taken.

The specific types of treatment recommended in these guidelines, such as "follow-up by computed tomography (CT) is important," even being recognized as the best practice today, are not necessarily covered by medical insurance.

\section{Future development}

These guidelines are the result of analyzing the status of this problem in Japan as of October 1999, and their constant revision according to the future development of medical science and care is anticipated. In addition, an inclusion of the evaluation of multiple injuries and brain injuries complicated by spinal cord injury is desirable in the future.

\section{Course of the Creation of the Guidelines (1st Edition)}

\section{Establishment and general rules followed by the preparatory committee in the creation of Guide- lines for the Treatment and Management of Severe Head Injuries}

At the Organizers' Meeting of the 21st Annual Meeting of the Japan Society of Neurotraumatology (March 25, 1998), it was decided to create the Guidelines for the Treatment and Management of Severe Head Injuries. Adults with closed head injuries and a GCS score of 8 or less were regarded as the target population. The guidelines were confirmed to be exclusively for academic purposes and would not regulate or restrict the contents or principles of treatment and management at individual medical institutions. In addition to pre-hospital care, resuscitation, and ICU management, the present status of indications for surgical and special types of treatment such as barbiturate therapy and hypothermia treatment would be analyzed. Japanese studies published over the past 10 years would be exhaustively reviewed, and differences compared with the contents of similar guidelines in the United States and Europe would be evaluated.

First meeting of the executive committee for the creation of Guidelines for the Treatment and Management of Severe Head Injuries (December 12, 1998)

The guidelines were clearly intended to be continuously revised after publication. The guidelines would be presented as a consensus of experts or combined with evidence. The guidelines would be drafted in an easy-to-read and easy-to-understand style. Multiple injuries would be excluded. 
Second meeting of the executive committee for the creation of Guidelines for the Treatment and Management of Severe Head Injuries (March 26, 1999)

The initial guidelines would be restricted to closed head injuries, and multiple injuries and injuries complicated by cervical spinal cord injuries would be excluded. The first edition would be created as soon as possible. References would be sorted according to topics and listed at the end of the guidelines. The guidelines would be published after approval by all organizers (executive committee members) of the Japan Society of Neurotraumatology.

Each executive committee member began to author the assigned parts of the guidelines in March 1998, and the 1st draft was completed in October. On the basis of the discussion at the 1st meeting of the executive committee for the creation of the Guidelines for the Treatment and Management of Severe Head Injuries in December the same year, a 2nd draft was prepared in June 1999. It was decided to itemize the contents as much as possible and to arrange the items in the order of reliability using the following expressions: 1 , ...is desirable; 2 , ...is often (performed); 3, ...can be (performed); 4, ...may be (performed); 5, ...is undesirable; and 6, ...may be regarded as a contraindication. In these guidelines, "...is desirable" is the strongest positive expression, followed by "...is often (performed)."

The final draft was prepared in October 1999 by evaluating the opinions of all members of the executive committee, and, after several sessions for editing, the guidelines were published in September 2000 .

\section{Course of Revision of the Guidelines}

March 29, 2003 (during the 26th Annual Meeting of the Japan Society of Neurotraumatology), Nara

It was decided to start revising the Guidelines for the Treatment and Management of Severe Head Injuries.

May 17, 2003 (during the Annual Meeting of the Japanese Congress of Neurological Surgeons), Osaka

Prior to the revision, it was decided to conduct a questionnaire survey on the application of the present guidelines and collect suggestions for the revision at the facilities of the organizers of the Japan Society of Neurotraumatology.

March 25, 2004 (during the 27th Annual Meeting of the Japan Society of Neurotraumatology), Tokyo

The results of the questionnaire survey were reported, and the following was decided regarding the revision procedure: The style of the present guidelines would be maintained in the revision; The newly published references (Japanese and international sources) after the preparation of the existing guidelines would be evaluated; New items concerning severe traumatic brain injury (TBI) in children and elderly people would be added; In addition to severe injuries, mild injuries that deteriorate into severe ones would also be mentioned; Contents mentioned repeatedly in the current guidelines would be edited to avoid repetitions.

May 14, 2004 (during the Annual Meeting of the Japanese Congress of Neurological Surgeons), Tokushima

The topics and sections of the revised guidelines draft and the persons assigned to them were determined.

October 6, 2004 (during the Annual Meeting of the Japan Neurosurgical Society), Nagoya

It was determined to submit the draft manuscript of the Revised Guidelines for the Management of Severe Head Injuries to the secretariat of the Japan Society of Neurotraumatology by the end of November 2004.

January 21, 2005 (during the Annual Meeting of the Japan Society of Neurosurgical Emergency), Nagoya

It was determined to publish the main text of the Revised Guidelines for the Management of Severe Head Injuries with annotations in the Journal of the Japan Society of Neurotraumatology.

March 24, 2005 (during the Annual Meeting of the Japan Society of Neurotraumatology), Omiya

It was decided that the contents of the manuscript should be restricted to the minimum essentials on the basis of the spirit described in the Introduction to the 1st Edition, and that representative committee members would perform final adjustments of the style and contents.

It was also determined that the contents be itemized as far as possible and that the levels of recommendation be expressed in the order of strength 11 being the strongest recommendation/indication and 5 the weakest recommendation, which is practically a contraindication) using the following expressions, similar to the current guidelines: 1 , ...is desirable; 2, ...is often (performed); 3, ...can be (performed); 4, ...may be (performed); 5, ...is undesirable; and 6, ...may be regarded as a contraindication. 


\section{Chapter 1: EMERgenCy CARE System AND NEUROSURGICAL DEPARTMENT (NEUROSURGEONS)}

\section{1-1. Pre-hospital Care}

The objective of pre-hospital care is to minimize secondary brain damage. For this purpose, it is desirable to perform the treatment essential for life support and promptly transport the patient to an appropriate medical facility based on the degree of emergency and severity ("load and go") as follows. i) Securing the airway (mandibular support); ii) correction of hypoxia (administration of high concentrations of oxygen); iii) correction of hypotension (compression hemostasis); iv) protection of the neck (manual protection of the cervical spine or total spinal immobilization using a cervical collar or backboard); and v) first aid for additional injuries.

In Japan, pre-hospital care is performed exclusively by ambulance crews belonging to local governments. i) It is desirable that physicians working for an emergency (casualty) room or medical facility to which the patient is transported give as much advice to the ambulance crew as possible (on-line medical control). ${ }^{*}$ Notes 1 and 2 Emergency care technicians (paramedics) can perform emergency medical treatment designated as specified medical actions (securing the airway or a venous line using specialized devices or equipment under the instructions of a physician, but such specified medical actions are presently permitted only in cardiopulmonary arrest. The contents of pre-hospital care performed for patients with head injury not in cardiopulmonary arrest is limited to respiratory management to prevent hypercapnia or hypoxemia (ambulances carry monitoring equipment such as an electrocardiography and $\mathrm{SaO}_{2}$ monitor, a ventilator for assisted respiration with a demand valve, etc.) It is desirable for the Local Medical Control Council to prepare and review guidelines for activities concerning the observation of injured patients, their treatment, evaluation of severity and emergency, and selection of facilities to transport them to and conduct follow-up evaluation with feedback and reeducation (off-line medical control).
Physicians on board an ambulance or helicopter can be directly involved in pre-hospital care based on one of the following methods: i) Ambulance crews are stationed at hospitals and can be called out with a physician; ii) An ambulance crew stationed near a hospital can pick up a physician at the hospital when it is called out; iii) An ambulance car or ambulance helicopter with a physician on board can directly go to the accident site or take over handing the patient from an ambulance crew during transport.

\section{1-2. Criteria for Transport to Special Facilities, Transport Methods, and Information System 1-2-1. Concerning all injury patients}

It is important to abide by 3 principles: i) accurate evaluation of severity ${ }^{*}$ Note 3 ; ii) appropriate selection of the hospital to transfer to, and iii) prompt transport. For this, it is desirable to select the medical institution according to the evaluation criteria for the severity and emergency of injuries (advance off-line medical control) (Fig. 1).

In emergencies requiring the fastest possible transport time, it is necessary to evaluate the degree of emergency and severity based on only visual inspection, auscultation, and palpation (Fig. 2).

\section{1-2-2. For patients with head injuries/distur-} bance of consciousness

Transport to an emergency hospital capable of investigations, including $\mathrm{CT}$, is desirable.

If symptoms of cerebral hernia in need of emergency treatment are detected, transport to a facility with a neurosurgeon (expert) is desirable. If the minimum resuscitation treatment such as securing the airway is necessary, it is desirable to perform it at the nearest medical facility and, then to transfer the patient to a facility with an expert.

Patients with moderate or more severe disturbance of consciousness (GCS scores 9-13) are often transported to a facility with an expert, but transport to an expert is desirable if the GCS score is 3-8 (JCS

\footnotetext{
*Note 1: Authorized emergency care technicians can perform endotracheal intubation if there are specific instructions given by a physician under on-line medical control.

${ }^{*}$ Note 2: Emergency care technicians can perform electric defibrillation without specific instructions by a physician. Ambulance crew members and firefighters other than emergency care technicians can also use an automated external defibrillator if they have completed the required training.

*Note 3: There have been objections to classifying an injury as severe or deteriorating to severe, if the level of consciousness is 100 or above on the JCS score (Table 1) at the initial evaluation. Based on the criteria for triage at the scene, using the criteria proposed by the College of Surgeons Committee on Trauma, injuries with a GCS score (Table 2) of 13 or less are graded as severe.
} 
Table 1 Japan Coma Scale (JCS) scores* (Ohta et al.; No Shinkei Geka, 1974)

\begin{tabular}{|c|c|}
\hline Grade & Consciousness level \\
\hline 1-digit code & $\begin{array}{l}\text { the patient is awake without any stimulation, and } \\
\text { is: }\end{array}$ \\
\hline 1 & almost fully conscious \\
\hline 2 & unable to recognize time, place, and him/herself \\
\hline 3 & unable to recall name or date of birth \\
\hline 2-digit code & $\begin{array}{l}\text { the patient can be aroused (then reverts to } \\
\text { previous state after cessation of stimulation) }\end{array}$ \\
\hline 10 & $\begin{array}{l}\text { easily by being spoken to (or is responsive with } \\
\text { purposeful movements, phrases, or words) }\end{array}$ \\
\hline 20 & $\begin{array}{l}\text { with loud voice or shaking of shoulders (or is } \\
\text { almost always responsive to very simple words } \\
\text { like yes or no, or to movements) }{ }^{\#}\end{array}$ \\
\hline 30 & only by repeated mechanical stimuli \\
\hline 3-digit code & $\begin{array}{l}\text { the patient cannot be aroused with any applied } \\
\text { mechanical stimuli, and: }\end{array}$ \\
\hline 100 & responds with movements to avoid the stimulus \\
\hline 200 & $\begin{array}{l}\text { responds with slight movements including } \\
\text { decerebrate and decorticate posture }\end{array}$ \\
\hline 300 & $\begin{array}{l}\text { does not respond at all except for change of } \\
\text { respiratory rate and rhythm }\end{array}$ \\
\hline
\end{tabular}

The 9-grade JCS has been more widely used in Japan as a simple and understandable coma scale compared with the 15-grade Glasgow Coma Scale. * "R" and "I" are added to the grade to indicate restlessness and incontinence of urine and feces, respectively: for example, 100-R and 30-RI. \#Criteria in parentheses are used in patients who cannot open their eyes for any reason.

Table 2 Glasgow Coma Scale (GCS) scores (Teasdale, Jennett; Lancet, 1974)

\begin{tabular}{|c|c|c|}
\hline Eye opening (E) & $\begin{array}{l}\text { Best verbal } \\
\text { response (V) }\end{array}$ & Best motor response $(\mathrm{M})$ \\
\hline 4. Spontaneous & 5. Oriented & $\begin{array}{l}\text { 6. Obeying verbal } \\
\text { commands }\end{array}$ \\
\hline $\begin{array}{l}\text { 3. To verbal } \\
\text { command }\end{array}$ & $\begin{array}{l}\text { 4. Confused } \\
\text { conversation }\end{array}$ & 5. Localizes pain \\
\hline 2. To pain & $\begin{array}{l}\text { 3. Inappropriate } \\
\text { words }\end{array}$ & $\begin{array}{l}\text { 4. Flexion/withdrawal to } \\
\text { pain }\end{array}$ \\
\hline 1. None & $\begin{array}{l}\text { 2. Incomprehensible } \\
\text { sounds } \\
\text { 1. None }\end{array}$ & $\begin{array}{l}\text { 3. Abnormal flexion due } \\
\text { to pain (upper limbs) } \\
\text { 2. Extension to pain } \\
\text { (upper limbs) } \\
\text { 1. None }\end{array}$ \\
\hline
\end{tabular}

$\operatorname{GCS}(3-15)=\mathrm{E}(1-4)+\mathrm{V}(1-5)+\mathrm{M}(1-6)$.

scores 30-300).

If depressed fracture, optic canal fracture, spaceoccupying intracranial lesion (such as an intracranial hematoma), etc., are observed, and if neurosurgical treatment or management such as continuous ICP monitoring is judged to be necessary, transfer to a facility with an expert is desirable.

If the patient has multiple injuries, transfer to a facility such as an emergency care center is desirable.
During transfer, it is desirable to continue the stabilization of respiratory and cardiovascular condition.

For transfer from a remote place, an ambulance with a physician on board belonging to an expert facility or emergency care center may be sent for the patient.

If there is no local medical facility matching the emergency or severity of the injury, the patient may be transported to a facility such as a remote tertiary medical institution using a helicopter, etc., bypassing the nearest medical facility (trauma bypass).

Information and communication devices such as FAX and the Internet should be used effectively to transfer the information related to the diagnosis and treatment. CT images, etc., may be transferred in this way, and an expert who can review them may give instructions concerning transport to an expert facility.

\section{1-3. Role of Neurosurgeons in Team Care at an Expert Facility, etc.}

\section{1-3-1. Secondary emergency care facilities}

It is desirable that a neurosurgeon takes the initiative throughout the entire care of head injuries, including the initial diagnosis and treatment, and preand postoperative management.

It is desirable that there is a specialized room for initial care, equipped for resuscitation, that the departments handling blood tests and transfusion, imaging diagnosis, and surgery are ready for immediate action, and that intensive postoperative care can be performed.

Since there may be other complicating injuries, it is desirable that consultation with general surgeons, orthopedic surgeons, etc., is available.

\section{1-3-2. Tertiary emergency care facilities}

Emergency care experts or trauma surgeons tend to take the lead, but the inclusion of a neurosurgeon in the care team is desirable.

In the initial diagnosis and treatment, it is desirable for the neurosurgeon to perform the treatment in cooperation with an emergency care specialist until the presence of other complicating injuries is excluded.

It is desirable that the neurosurgeon is responsible for the performance of surgery and the postoperative management of head injuries.

In patients with multiple injuries including head injuries, it is desirable that a neurosurgeon performs the craniotomy, however the order of treatment procedures has to be determined and general management be performed in cooperation with a physician in charge of the emergency/intensive care (the team leader). 
1st stage

Physiological evaluation
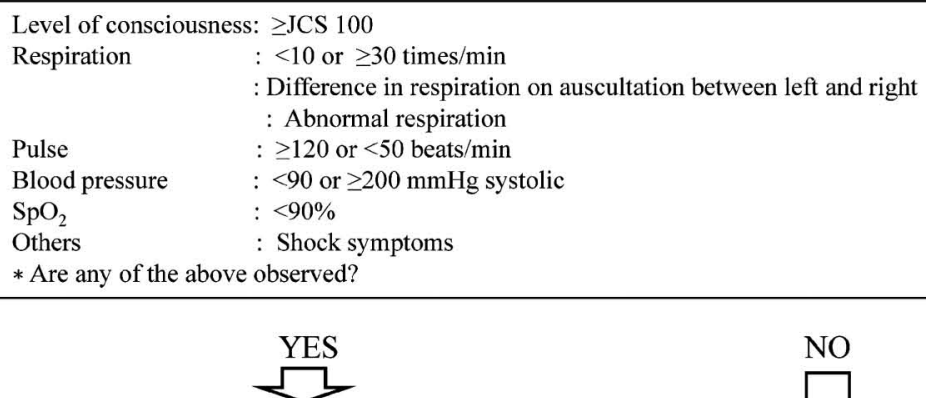

Considered severe or worse $(* 1)$

2nd stage

Anatomical evaluation

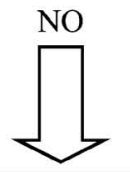

- Facial bone fracture

- Cervical or thoracic subcutaneous emphysema

- Marked dilation of the external jugular vein

- Flail chest

- Abdominal distension, increased abdominal wall tension and rebound tenderness

- Pelvic fracture (unstable pelvis, tenderness, difference in leg length)

- Bilateral femoral fracture (deformation, hemorrhage, swelling, and tenderness in the femoral region,

difference in leg length)

- Penetrating injury (stab injury, gunshot wound, impalement injury, etc.) to the head, chest, abdomen, neck,

or inguinal region

- Complicated by $15 \%$ or wider burn injury, burn injury of the face or airway

- Degloving injury

- Multiple finger amputations (e.g., 2 fingers, 3 toes)

- Limb amputation

- Limb paralysis

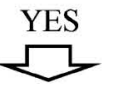

Considered severe or worse $(* 1)$ 3rd stage

Circumstances of injury

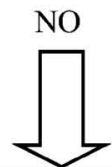

$\begin{array}{ll}\text { - Death of fellow passengers } & \text { - Turn-over of the vehicle } \\ \text { - Thrown out of the vehicle } & \text { - Distance between the fallen motorcycle and rider is large } \\ \text { - Run over by a vehicle } & \text { - Collision of an automobile with a pedestrian or bicycle } \\ \text { - Sent flying over a distance of } 5 \mathrm{~m} \text { or more } & \text { - Being caught in a machine } \\ \text { - Vehicle was severely damaged } & \text { - Torso jammed between objects } \\ \text { - More than } 20 \text { minutes were needed for rescue } & \text { - Fall from height }\end{array}$

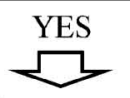

Considered severe or worse $(* 2)$

\section{NO}

Considered moderate or milder

In principle, the order of priority of the severity and emergency evaluation is the $1 \mathrm{st}, 2 \mathrm{nd}$, and 3rd stages. $(* 1) \quad$ If the injury is judged to be severe or worse, select a tertiary emergency care facility such as an emergency care center, secondary emergency care institution, or local general hospital with comparable facilities.

(*2) In principle, follow the policy shown in $* 1$, but if it is difficult to find a hospital to admit the patient, ask for a physician's advice or instruction.

\section{-----Points of caution-----}

\section{Other evaluations}

If the patient has the following conditions, and if it is difficult to find a hospital to admit the patient, ask for advice or instructions from a physician, because the injury may be regarded as severe even if it does not meet the criteria of the 1st to 3rd stages of evaluation:

- Child or elderly person - Dialysis - Medicinal poisoning

- History of cardiac or respiratory disease $\quad \cdot$ Malignant neoplasm 1 Morbid obesity

$\begin{array}{ll}\text { - Diabetes (especially if the patient is using insulin) } & \cdot \text { Use of an anticoagulant } \\ \text { - Liver cirrhosis } & \cdot \text { Hemorrhagic disease (purpura, hemophilia, etc.) }\end{array}$

Fig. 1 Criteria for severity and emergency evaluation of injuries for emergency transport. Cited from the Criteria for Severity and Emergency Evaluation of Injuries in the Report of the Committee on the Criteria for Severity and Emergency Evaluation of Injuries, Foundation of Ambulance Service Development and the figure on page 187 of the Japan Prehospital Trauma Evaluation and Care. JCS: Japan Coma Scale. 


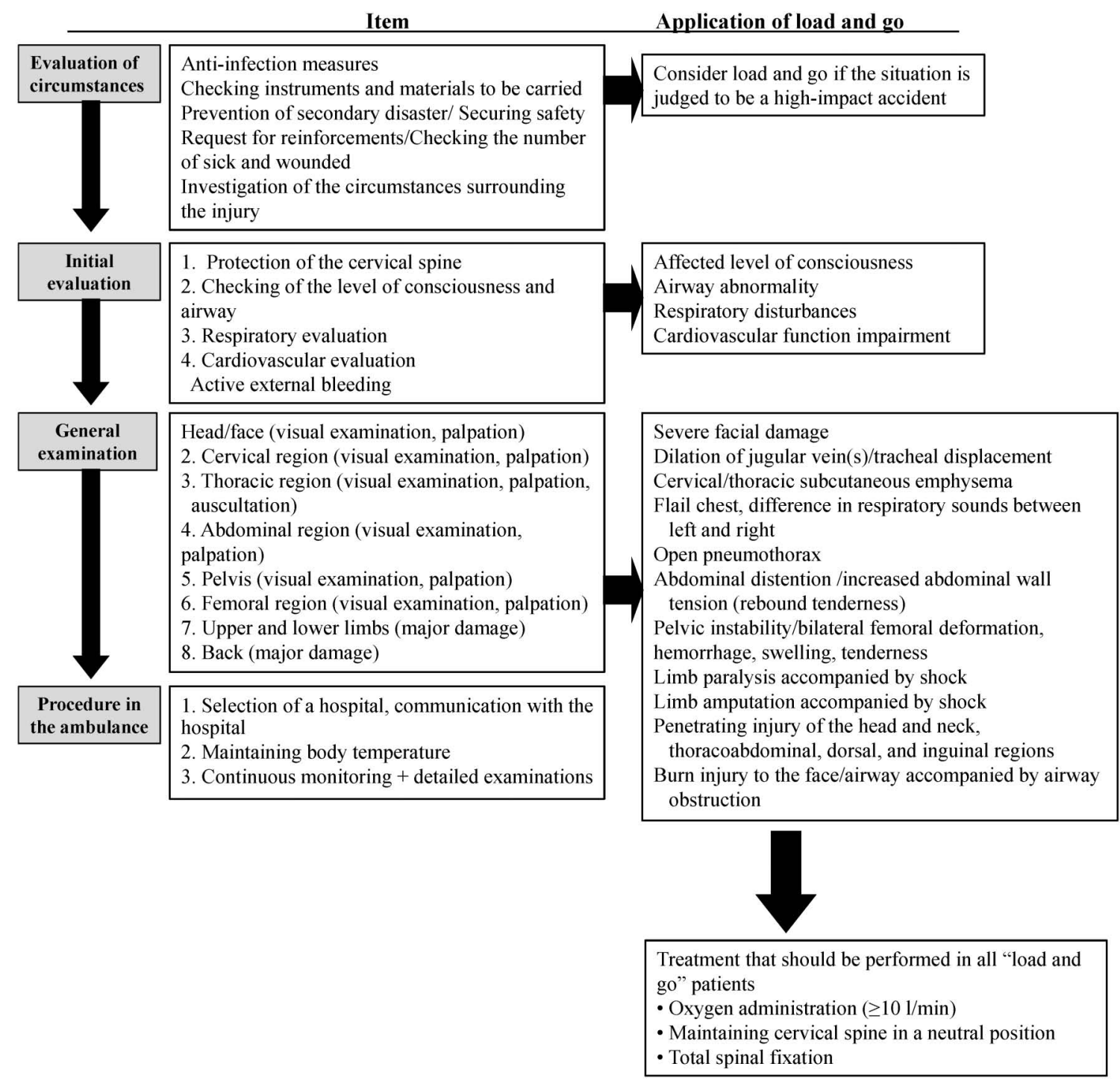

Fig. 2 Flow chart of load and go according to the Japan Prehospital Trauma Evaluation and Care (JPTEC ${ }^{\mathrm{TM}}$ ). Cited from the figure on page 11 of the JPTEC.

It is desirable for neurosurgeons to play the same role in the local medical service system as at the secondary emergency care facility even at a hospital regarded as a tertiary emergency care facility, if there is no existing emergency/intensive care team.

If a neurosurgeon cannot regularly participate in the team, it is desirable for an emergency care physi- cian or the team as a whole to perform the initial treatment, the pre- and postoperative management maintaining contact with a surgeon (the neurosurgeon in-charge of the surgical treatment). If only conservative treatment (including continuous monitoring of the ICP) is performed, a neurosurgeon may not be directly involved.

\section{Chapter 2: Initial Treatment to Protect the Brain}

\section{2-1. Initial Examination and Treatment of Inju- ries}

Even if the possibility of simple injury of the head is considered high, it is desirable to perform the treatment according to the JATEC ${ }^{\mathrm{TM}}$ until life- threatening injuries at other sites are excluded.

It is important in head injuries to minimize secondary brain damage due to extracranial as well as intracranial factors at the initial examination and treatment. For this purpose, it is desirable to begin 
the primary assessment and resuscitation promptly after the arrival of the patient.

Preparations for the acceptance of patients are as follows. i) It is desirable that a physician directly takes telephone calls requesting the acceptance of trauma patients. ii) Devices such as a resuscitation set, portable X-ray machine, and diagnostic ultrasound equipment are often prepared for the initial examination and treatment. iii) It is desirable to take standard infection prevention measures.

Primary assessment and resuscitation to secure stability of the general condition are as follows. i) If abnormality of physiologic parameters is detected at the primary assessment, it is desirable to resuscitate immediately. Resuscitation includes not only cardiopulmonary resuscitation but also all types of emergency treatment necessary to maintain life. ii) During the primary assessment, resuscitation is often performed in the order of: airway, respiration, and circulation. iii) If the GCS score is 8 or less, it is desirable to secure the airway by endotracheal intubation, etc. It is desirable to protect the cervical spine while securing the airway. iv) It is desirable to maintain sufficient oxygenation and ventilation. In severely injured patients, high-concentration oxygen administration and assisted ventilation are often performed. v) It is desirable to start treatment immediately if a life-threatening thoracic injury is detected. vi) If there is abnormal respiration or circulation, it is desirable to promptly perform chest and pelvic radiography and abdominal ultrasonography. Even if there is no respiratory or cardiovascular abnormality, it is still desirable to perform the above imaging investigations if affected consciousness level is detected. vii) If there are symptoms of shock, it is desirable to give initially rapid 1-2 l infusion for extracellular fluid supplementation and examine response, as well as to examine whether there is obstructive shock (cardiac tamponade, tension pneumothorax). viii) On the primary assessment, it is desirable to examine the following neurological clinical parameters, in particular: GCS, pupillary findings, and presence of focal deficit: hemiplegia, etc. ix) If the GCS score is 8 or less, or if the GCS score has deteriorated rapidly by 2 or more, and anisocoria or hemiplegia (signs of cerebral hernia) is observed, it is desirable to contact immediately an expert and perform a CT. $\mathrm{x}$ ) Undressing is often necessary to search for life-threatening injuries. xi) If the patient has a high fever, it is desirable to promptly decrease the body temperature to the normal range. xii) If hypothermic patients are at risk of massive hemorrhage, it is desirable to warm them promptly for preservation of blood coagulation and hemostatic properties.
Reference: ABCDE approach: Airway, evaluation and securing the airway and protection of the cervical spine; Breathing, respiratory evaluation and treatment for life-threatening thoracic injuries; Circulation, cardiovascular evaluation, resuscitation, and hemostasis; Dysfunction of central nervous system, evaluation of life-threatening disorders of the central nervous system; and Exposure and environmental control, undressing and body temperature management.

Secondary assessment for close examination of the injury includes followings. i) If there is severe disturbance of consciousness with a GCS score of 8 or less, a rapid decrease in the level of consciousness, or signs of cerebral hernia are observed, CT is performed at the beginning of the secondary assessment, and respiratory and cardiovascular management performed during the assessment. ii) It is desirable to examine for the following in the secondary assessment of the head: injuries and depressed fractures concealed under the hair; spectacle hematoma ("raccoon" eyes, "Brillen" hematoma) or Battle's sign due to cranial base fracture; ocular or orbital injuries; and hemorrhage or cerebrospinal fluid leakage from the external auditory meatus or oronasal cavity. iii) In patients suspected to have cranial base fracture, it is desirable to insert a gastric tube orally.

\section{2-2. Securing the Airway and Respiratory Management \\ 2-2-1. Securing the airway}

i) In all injury patients, securing the airway is the first priority. Reliable securing of the airway by tracheal intubation, in principle, is desirable if the GCS score is 8 or less, or if the best motor response of the GCS score is 5 or less. ii) Endotracheal intubation should be performed orally, in principle. If the patient is non-responsive, apneic, or shows agonal respiration, it is desirable to consider the condition as an "airway emergency" and immediately perform direct-vision oral intubation. iii) If the condition is not an "airway emergency," prompt endotracheal intubation using sedatives and muscle relaxants is often performed, in principle. However, if intubation is expected to be difficult due to obesity, a short neck, etc., nasal or endoscopic intubation is often selected. iv) Since many sedatives may cause hypotension due to circulatory suppression, it is desirable to administer them with caution. In consideration of the necessity for repeated evaluation of neurological condition, the use of short-acting sedatives (such as propofol) is desirable. v) It is desirable to avoid laryngeal distention or the use of depolarizing muscle relaxants (such as succinylcholine) under 
insufficient sedation, because that may cause an increase in the ICP. vi) If tracheal intubation is difficult due to marked facial injury, etc., a surgical procedure to secure the airway such as thyrocricotomy is often selected. vii) The cervical collar should be removed if it interferes with laryngeal extension, but manual fixation of the cervical spine in the median neutral position is desirable during laryngeal extension. Priority is given to securing the airway and cervical spine fixation can be sacrificed if necessary.

2-2-2. Indications for securing the airway in injury patients

i) Airway obstruction: If securing the airway by the manual technique is insufficient; possibility of aspiration of blood or vomitus; and risk of airway narrowing due to hematoma, damage, etc. ii) Securing the airway in anticipation of respiratory management: apnea; hypoventilation and hypoxemia (not corrected by oxygen administration). iii) Severe hemorrhagic shock/cardiac arrest. iv) Decrease in the level of consciousness (GCS score $<8$ ), etc.

\section{2-2-3. Respiratory management}

i) All patients with severe injuries are often administered high-concentration oxygen (at 10-15 $1 /$ min using a face mask with a reservoir) until it becomes clear that there is no risk of death. Particularly, it is desirable to administer high-concentration oxygen in patients with a problem regarding the respiration, circulation, or consciousness. ii) It is desirable to perform respiratory management at initial care with the following targets: arterial blood oxygen saturation $\left(\mathrm{SpO}_{2}\right)>95 \%$, arterial blood oxygen partial pressure $\left(\mathrm{PaO}_{2}\right)>80 \mathrm{mmHg}$; and arterial blood carbon dioxide partial pressure $\left(\mathrm{PaCO}_{2}\right)$ or end-tidal carbon dioxide tension $\left(\mathrm{PetCO}_{2}\right)-30-35$ mmHg during a period of elevated ICP, 35-45 mmHg during a period of normal ICP, and $\mathrm{PaCO}_{2}$ may be temporarily controlled to $30 \mathrm{mmHg}$ or less during the preparation for surgical decompression, etc. iii) It is desirable to treat the following conditions as soon as they are detected: flail chest, open pneumothorax, tension pneumothorax, massive pneumothorax, and massive airway hemorrhage, etc.

\section{2-3. Cardiovascular Management}

It is desirable to give priority to the prevention of shock and resuscitation over treatment for intracranial lesions.

If there are symptoms of shock, it is desirable to give 1-2 l of extracellular fluid supplement by rapid intravenous infusion as an initial therapy and to examine the response. If the patient shows no response or only a temporary response to the initial infusion therapy, priority is often given to hemostatic procedures (surgery, trans-arterial embolization, etc.)

Before concluding that the condition is a neurogenic shock, it is desirable to perform differential diagnosis with the following conditions: i) hypoxemia (upper airway obstruction, pulmonary contusion, atelectasis, central pulmonary edema); ii) hemorrhagic shock due to injuries at other sites (thoracic cavity, abdominal cavity, retroperitoneal cavity), iii) obstructive shock (cardiac tamponade, tension pneumothorax); and iv) blunt cardiac injury, etc.

Intraperitoneal fluid accumulation and cardiac tamponade are often diagnosed promptly by focused assessment with sonography for trauma.

The following are desirable as targets of circulatory management at the initial examination and treatment: i) Patients with uncomplicated head injuries: systolic blood pressure $>90-100 \mathrm{mmHg}$ and hemoglobin 7-10 g/dl; ii) Patients with complicated head injuries: systolic blood pressure $>120 \mathrm{mmHg}$, mean arterial blood pressure $>90 \mathrm{mmHg}$, cerebral perfusion pressure (CPP) $>60-70 \mathrm{mmHg}$ (if the ICP is measured), and hemoglobin $>10 \mathrm{~g} / \mathrm{dl}$.

In patients with hemorrhagic shock, it is desirable to perform promptly initial infusion therapy even if there are head injuries. However, intracranial hypertension may be exacerbated with the resolution of shock due to rapid dilation of the cerebral vasculature.

To prevent hyperglycemia, a glucose-free solution is desirable as extracellular fluid supplementation used for initial infusion therapy. Avoidance of infusion overload is desirable to prevent cerebral edema. Hypertonic saline or sodium lactate solutions may be used to reduce the infusion volume and prevent cerebral edema.

In the secondary assessment, in principle, head CT is performed after stabilization of the cardiovascular condition. At facilities that can simultaneously perform hemostatic procedures against shock and surgery for head injuries, head CT may be performed preoperatively in anticipation of simultaneous surgery if hemodynamics can be maintained by rapid infusion.

For the management of hypertension considered to be Cushing's phenomenon, it is desirable to give priority to the correction of intracranial rather than systemic hypertension. There is no clear guideline concerning to what level hypertension may be permissible.

It is desirable to use antihypertensive agents carefully, because many of them dilate the cerebral vasculature and exacerbate intracranial hypertension. The calcium-blocker diltiazem has been reported to exhibit a relatively mild effect on the ICP. 


\section{2-4. Recognition and Treatment of Life-Threa- tening Brain Herniation}

A GCS score of 8 or less, rapid exacerbation of the GCS score by 2 or more, anisocoria, hemiplegia, etc., often indicate a life-threatening brain herniation.

A large space-occupying lesion, a 5-mm or greater brain midline shift, and compression or disappearance of the basal cisterns often indicate lifethreatening brain herniation.

Even if a life-threatening brain herniation is diagnosed, it is desirable to give priority to the normalization of respiration and circulation if they are abnormal.

It is desirable to perform immediately emergency surgery for life-threatening brain herniation due to a space-occupying lesion.
With the following events, ultra-emergency trephination or a small craniotomy may be performed at the initial examination in the treatment room or ICU: i) If the condition is considered to be extremely urgent, so that there is no time for normal craniotomy. ii) When further transfer of the patient is decided to be impossible due to complicating injuries, etc.

As a treatment for a life-threatening brain herniation, before surgery for the space-occupying lesion, a rapid drip infusion of mannitol at $0.25-1.0 \mathrm{~g} / \mathrm{kg}$ is desirable. When using mannitol, it is desirable to pay attention to a possible decrease in the circulating blood volume.

See the chapter on ICU management for other general treatment for intracranial hypertension.

\section{ChAPTER 3: ICU MANAgEMENT}

\section{3-1. Imaging Examinations and Monitoring 3-1-1. Imaging evaluation}

Neuroimaging evaluation on admission: CT, in particular, is essential, because it provides very important information concerning the selection of the therapeutic strategy including the priority of treatment in cases of multiple injuries, judgment of severity, and prognosis.

CT: CT is very important for the early diagnosis of deteriorating brain edema or the appearance or enlargement of an intracranial hematoma. While importance should be given to changes in clinical condition, increased ICP, or reduced CPP, follow-up by $\mathrm{CT}$ is desirable.

Magnetic resonance (MR) imaging: Although MR imaging is not available at many facilities as an acute stage emergency examination, it is often more useful than CT, particularly regarding the following: i) Early diagnosis of parenchymal lesions of the brain such as brain contusion, brain edema, and petechial hemorrhages. ii) Diagnosis of cranial base lesions, which are difficult to be detected by CT due to bone artifacts. iii) Diagnosis and pathological analysis of diffuse brain injuries, particularly diffuse axonal injury (Table 3).

\section{3-1-2. Monitoring}

The following tends to be useful for specific monitoring related to function of the brain and nerves (neuromonitoring): i) Physiological monitoring: electroencephalography (EEG); evoked potentials (auditory brainstem response, somatosensory evoked potential, motor evoked potential, etc.), eventrelated potentials (P300), etc. ii) Monitoring of brain circulation and metabolism: ICP and CPP; cerebral blood flow (CBF), cerebral metabolic rate of oxygen, and arteriovenous oxygen content difference; imaging studies of brain circulation and metabolism (single photon emission tomography, xenon-CT, dynamic CT, positron emission tomography, etc.; transcranial Doppler ultrasonography and color Doppler sonography; oxygen saturation at the bulb of the jugular vein $\left(\mathrm{SjO}_{2}\right)$ and transcranial monitoring of oxygen saturation measured by near-infrared spectroscopy, partial oxygen pressure in the cerebrospinal fluid or brain tissue; brain temperature (jugular vein blood temperature, brain parenchymal temperature, etc.); biochemical measurements of products of energy metabolism, free radicals, cytokines, acidbase balance, etc., and microdialysis, etc. iii) Multimodality monitoring: Using a combination of i) and ii).

These monitoring techniques tend to be used for

Table 3 Computed tomography (CT) classification of the Traumatic Coma Data Bank (Marshall, et al.; J Neurosurg, 1991)

\begin{tabular}{|c|c|}
\hline Category & Definition \\
\hline Diffuse injury I & No visible intracranial pathology seen on CT \\
\hline Diffuse injury II & $\begin{array}{l}\text { Cisterns present with midline shift } 0-5 \mathrm{~mm} \\
\text { and/or: } \\
\text { Lesion densities present } \\
\text { No high or mixed density lesion }>25 \mathrm{~cm}^{3}\end{array}$ \\
\hline $\begin{array}{l}\text { Diffuse injury III } \\
\text { (swelling) }\end{array}$ & $\begin{array}{l}\text { Cisterns compressed or absent with midline } \\
\text { shift } 0-5 \mathrm{~mm} \text {, no high or mixed density } \\
\text { lesion }>25 \mathrm{~cm}^{3}\end{array}$ \\
\hline $\begin{array}{l}\text { Diffuse injury IV } \\
\text { (shift) }\end{array}$ & $\begin{array}{l}\text { Midline shift }>5 \mathrm{~mm}, \text { no high or mixed } \\
\text { density lesion }>25 \mathrm{~cm}^{3}\end{array}$ \\
\hline $\begin{array}{l}\text { Evacuated mass } \\
\text { lesion }\end{array}$ & Any lesion surgically evacuated \\
\hline $\begin{array}{l}\text { Nonevacuated } \\
\text { mass lesion }\end{array}$ & $\begin{array}{l}\text { High or mixed density lesion }>25 \mathrm{~cm}^{3} \text {, not } \\
\text { surgically evacuated }\end{array}$ \\
\hline
\end{tabular}


not only the pathophysiological analysis of patients with severe head injuries, but also evaluation of the therapeutic effects and prognosis. Particularly, the ICP and CPP are often useful for the management of patients. However, many others are employed less frequently in Japan than in Western countries, and so need further evaluation.

\section{3-2. Indications for ICP Monitoring}

ICP monitoring is appropriate in patients with: GCS score of 8 or less; hypotension (systolic arterial blood pressure $<90 \mathrm{mmHg}$ ); and abnormal CT findings, e.g. midline shift, compressed basal cisterns.

ICP monitoring is appropriate in patients receiving barbiturate or hypothermia treatment.

Ventricular, parenchymal or subdural catheter connected to a catheter tip strain gauge is a reliable method of monitoring ICP.

ICP monitoring may be not indicated in patients with severe head injury and normal CT findings.

ICP monitoring may be done in patients with altered level of consciousness due to heavy sedation.

\section{3-3. Treatment Thresholds of ICP and CPP}

Threshold of ICP: Values of 15 to $20 \mathrm{mmHg}$ are desirable to start aggressive treatment. Caution: Neurological deterioration may occur without ICP elevation in patients with uncal herniation.

Threshold of CPP: Values of 60 to $70 \mathrm{mmHg}$ or less are required before starting aggressive treatment.

3-4. Surgical Treatment (External Decompression, Internal Decompression, Cerebrospinal Fluid Drainage)

\section{3-4-1. External decompression}

Decompressive craniotomy may be performed after the removal of a hematoma such as an acute subdural hematoma.

During decompressive craniotomy, duraplasty, or widening osteoplasty may be performed to enlarge the cranial cavity.

\section{3-4-2. Internal decompression}

If the ICP exceeds $30 \mathrm{mmHg}$ even after general treatment to control it or if there is obvious deterioration of neurological condition such as a decrease in the level of consciousness, resection at the site of brain contusion is often performed to prevent secondary brain damage.

Internal decompression may be performed in brain contusion patients who are admitted with normal speech and later deteriorate.

\section{3-4-3. Cerebrospinal fluid drainage}

Cerebrospinal fluid drainage is performed relatively widely in the United States for the treatment of increased ICP and to obtain a route for ICP monitoring, but not in Japan because of the difficulties in puncturing narrow ventricles, difficulty in ICP control due to ventricular collapse, and complications including hemorrhage and infection.

\section{3-5. Sedation, Pain Control, Immobilization 3-5-1. Sedation}

Diazepam: Diazepam may be used for epilepsy but is not suitable for patients requiring frequent evaluation of the level of consciousness, because of its relatively long half-life and period of action.

Midazolam: Midazolam reduces the CBF and cerebral oxygen consumption, so tends to be used safely and effectively for anesthesia and sedation of patients with increased ICP.

Barbiturates: Barbiturates markedly suppress the circulation, and caution concerning the induction of asthma is also necessary, but transition to barbiturate therapy for the treatment of status epilepticus, protection of the brain, and management of the ICP is possible.

Propofol: i) Propofol provides satisfactory sedation in patients with severe head injuries under controlled respiration. Moreover, it allows early neurological evaluation because of rapid emergence. ii) Propofol is characterized by rapid metabolism, lowlevel accumulation, and favorable emergence. iii) Caution regarding a decrease in the blood pressure is necessary, but this also has a brain-protective effect. iv) Compared with thiopental, propofol can also be used in patients with a history of asthma. Also, the times to emergence and extubation respectively are shorter than with midazolam. v) Propofol is generally contraindicated in the intensive care of children.

Dexmedetomidine: Dexmedetomidine allows the checking of changes in the level of consciousness and is also expected to have a brain-protective effect.

\section{3-5-2. Immobilization (muscle relaxants)}

Vecuronium: Vecuronium has a shorter duration of action than pancuronium, so facilitates neurological diagnosis and tends to be used widely.

\section{3-6. Elevation of the Head}

Elevation of the head is useful for the control of ICP, and the angle is often adjusted to $15-30^{\circ}$.

Elevation of the head by $30^{\circ}$ or more is undesirable, because this reduces the CPP and produces adverse effects.

\section{3-7. Hyperventilation Therapy}

If there is no increase in the ICP ( $>20 \mathrm{mmHg})$, it is desirable to maintain $\mathrm{PaCO}_{2}$ at $25 \mathrm{mmHg}$ or above by 
endotracheal intubation and controlled respiration.

Blind hyperventilation should be avoided. Particularly, it is desirable to avoid hyperventilation $\left(\mathrm{PaCO}_{2}\right.$ $<35 \mathrm{mmHg}$ ) without ICP monitoring within 24 hours after injury.

During hyperventilation therapy, arterial blood gas analysis or the measurement of the end-tidal partial carbon dioxide pressure is essential, and monitoring of the ICP and $\mathrm{SjO}_{2}$ is desirable.

Hyperventilation therapy is often initiated if the ICP cannot be controlled at $20 \mathrm{mmHg}$ or less by sedative or muscle relaxant administration, cerebrospinal fluid drainage, or the administration of a hypertonic solution.

Hyperventilation therapy discontinuation is desirable if the ICP can be controlled at $<20 \mathrm{mmHg}$ by other treatments.

If the ICP cannot be controlled to $20 \mathrm{mmHg}$ or less even by reducing the $\mathrm{PaCO}_{2}$ to $30-35 \mathrm{mmHg}$, the $\mathrm{PaCO}_{2}$ may be reduced to $25-30 \mathrm{mmHg}$, but it is desirable to discontinue hyperventilation at this level as quickly as possible.

\section{3-8. Mannitol, Glycerol, Diuretics}

In patients showing or suspected to have ICP, the appropriate administration of mannitol or glycerol is useful for the control of the ICP.

It is desirable for the plasma osmotic pressure before administration to be $310 \mathrm{mOsm}$ or less.

An effective dose is usually $0.25-1.0 \mathrm{~g} / \mathrm{kg}$.

It is often suggested that repeated bolus administrations are more effective than continuous administration.

\section{3-9. Barbiturate Therapy}

Initiation of barbiturate therapy may be considered if intracranial hypertension could not be controlled with maximum standard treatment. Usual dose: pentobarbital $2-5 \mathrm{mg} / \mathrm{kg}$ body weight or thiopental $2-10 \mathrm{mg} / \mathrm{kg}$ as a bolus, followed by continuous infusion of pentobarbital $0.5-3 \mathrm{mg} / \mathrm{kg} / \mathrm{hr}$ or thiopental 1-6 $\mathrm{mg} / \mathrm{kg} / \mathrm{hr}$.

\section{3-10. Steroids}

While the negative view that glucocorticoids (steroids) are ineffective for the treatment of head injuries is shared by many researchers, prednisolone or betamethasone may, in practice, be administered intravenously.

Sufficient attention to gastrointestinal bleeding and hyperglycemia as side effects of steroids is also necessary.

\section{3-11. Hypothermia (Brain Hypothermia)}

Although hypothermia reduces the ICP, it does not improve the outcome.

Hypothermia has unfavorable outcome in elderly people, but tends to result in favorable outcome in children.

Hypothermia may increase the incidences of complications such as infection, arrhythmia, hypokalemia, and thrombocytopenia.

Concerning hypothermia, no consensus has been reached regarding the target body temperature, duration, temperature recovery method, patient selection (except age), etc.

\section{3-12. Therapeutic Procedures for Increased ICP}

For ICP > 15-25 mmHg: i) Check the respiratory condition, intubate the patient if necessary, and maintain the $\mathrm{SpO}_{2}$ at $95 \%$ or above. If respiration is weak, assisted ventilation is desirable. ii) It is desirable to elevate the head (by the cranial side of the bed). Caution not to flex the neck and impair venous return is necessary. iii) Intravenous administration of high-osmotic pressure diuretics (mannitol) or glycerol is desirable. iv) Hyperventilation may be performed to maintain the $\mathrm{PaCO}_{2}$ at $30-35 \mathrm{mmHg}$.

For ICP $>20-25 \mathrm{mmHg}$ : If the ICP is difficult to control even by i) to iv) in above, it is desirable to perform CT again and advance to the next step. i) Barbiturate (thiopental, pentobarbital, etc.) therapy may be performed. ii) Hypothermia treatment may be administered. iii) External or internal decompression may be performed.

\section{3-13. Antiepileptics}

Antiepileptics are reported to be effective for the treatment of early epilepsy, without significant difference in the incidence of late epilepsy between treated and untreated patients. Many researchers support the view that antiepileptics are ineffective in preventing epileptogenic foci development. Some researchers have suggested that only zonisamide has preventive effect.

Antiepileptics may be administered to the following patients: i) patients showing abnormalities on CT, particularly those found to have brain parenchymal injuries; ii) patients with early-onset epilepsy; and iii) young patients.

Phenytoin, carbamazepine, zonisamide, and phenobarbital are often used. Many researchers hold the view that valproic acid is a selective drug for generalized epilepsy and is not suitable for the treatment of traumatic epilepsy. Carbamazepine has not been sufficiently evaluated.

Since early epilepsy deteriorates brain injuries, it is desirable to avoid using antiepileptics. i) Since antiepileptics have a brain-protective effect, it is desirable to use them promptly in patients with brain inju- 
ries. ii) If antiepileptics are used, it is desirable to start their administration within 24 hours after injury and continue the therapy for 3 months until brain edema has subsided and cerebral circulation is stabilized. iii) Antiepileptic treatment is often continued for 2 years in patients with severe brain injuries.

Against late epilepsy: i) As in epilepsy in general, it is desirable to start administration of antiepileptics. ii) Phenytoin, carbamazepine, zonisamide, and phenobarbital, which are effective drugs for partial epilepsy, are often used. iii) During the administration of antiepileptics, it is desirable to perform periodically EEG studies and check plasma drug lev- els. iv) Traumatic epilepsy generally has a favorable prognosis and is resolved in $50 \%$ of the patients in 5 years. However, as it develops into refractory epilepsy in some patients, it is desirable to discontinue the administration of antiepileptics in seizurefree patients after careful evaluation.

\section{3-14. Nutrition}

Enteral or parenteral nutrition should be initiated early in order to attain full caloric replacement by day 7 after injury.

Blood glucose level should be controlled within the range of $100-200 \mathrm{mg} / \mathrm{dl}$.

\section{Chapter 4: SURgical Indications AND Procedures}

\section{4-1. Closed Depressed Skull Fracture}

Whether reduction of depressed fracture leads to an improvement of neurological deficit or the incidence of traumatic epilepsy (late epilepsy) has not been established.

- Indications: i) presence of 1-cm or greater depression or severe brain contusion; ii) presence of esthetically unacceptable cranial deformity; and iii) compression of the venous sinuses, etc.

- Methods: Elevation of depressed bone fragments or their repositioning by craniotomy.

\section{4-2. Open Skull Depressed Fracture}

If there is dural damage (penetrating head injury), it is important to promptly perform dural closure. If there is no dural damage (non-penetrating head injury), only sufficient irrigation, débridement, and closure of the scalp wound are necessary.

- Indications: i) Markedly contaminated wound; ii) severe contusion or comminuted fracture; iii) exposure of the brain parenchyma or situations suggestive of dural damage such as the leakage of cerebrospinal fluid; iv) presence of bone fragments in the brain; v) uncontrollable hemorrhage related to bone fragments (damage of a venous sinus, etc.); vi) disorders of venous return due to compression of a venous sinus by depressed bone fragments; vii) 1 -cm or greater depression or severe brain contusion; and viii) esthetically unacceptable cranial deformity, etc.

- Timing: Surgery within 24 hours is desirable. The infection rate clearly increases if surgery is performed more than 48 hours after injury.

- Methods: i) Debridement: If the wound is contaminated, specimens for culture should be taken. ii) Dural closure: Not only scalp closure by suturing but also dural closure must be ensured (particularly when the wound is contaminated). If the dural defect is large and difficult to close by suturing, duraplasty using autologous grafts such as periosteum, fascia, or aponeurosis should be performed (tissues with a rich blood supply are more resistant to infection). iii) Timing of cranioplasty: If there is a markedly contaminated wound, severe brain laceration, or comminuted fracture, if surgery is performed after more than 48-72 hours after injury, if bone fragments are present in the brain, or if there is brain protrusion, etc., two-stage surgery (removing contaminated bone fragments first and performing cranioplasty later) should be considered. The timing of cranioplasty should be determined according to the state of contamination and postoperative course. It should be performed after confirming adequate control of infection.

\section{4-3. Penetrating Injuries}

Penetrating injuries may be caused by objects used in daily life such as an umbrella, needle, and chopsticks, as well as a bullet, knife, and shard of glass. The route of entry may be transcranial, transorbital, transnasal, transbasal, etc.

- Indications: All penetrating head injuries are indicated for surgical treatment, but a gunshot wound, which causes extensive brain damage, is often not regarded as an indication.

- Timing: Surgery should be performed as promptly as possible. Angiography may be performed preoperatively if damage of a venous sinus or artery is strongly suspected.

- Methods: i) Removal of the object penetrating the brain before entry into the operation room must usually be avoided. ii) It is desirable to perform a craniotomy in the area around the penetrating object and carefully remove the site of penetration using a Luer bone nibbler or a drill. iii) Dural opening is often performed radially around the penetration site. iv) It is desirable to remove any subdural and in- 
tracerebral cloth and remove debris around the penetrating object. v) Carefully remove the penetrating object. Pay attention to the risk of damaging blood vessels. vi) It is desirable to perform tight closure of the dura using the femoral fascia, etc. vii) If the wound is contaminated, cranioplasty should be performed after sufficient control of infection according to the degree of contamination and postoperative course. It is often performed 3-6 months after injury.

$\checkmark$ Complications: Complications include meningitis, brain abscess, cerebrospinal fluid leakage, and traumatic intracranial aneurysms.

\section{4-4. Acute Epidural Hematoma}

- Indications for surgical intervention: i) Surgery is indicated as a principle for acute epidural hematoma $\geq 1-2 \mathrm{~cm}$ in thickness, $\geq 20-30 \mathrm{ml}(\geq 15-20 \mathrm{ml}$ in the posterior fossa), or in the presence of concomitant hematoma with different location. ii) Emergency craniotomy is indicated in the case of a progressively worsening neurological deficit (in particular, frequent neurological examinations and follow-up CT scanning are required within 24 hours of the injury). iii) Conservative management, with close clinical observation, is reasonable if there is no neurological deficit.

- Timing: Surgery performed as soon as possible is desirable.

- Methods: Craniotomy with hematoma evacuation is the principle.

\section{4-5. Acute Subdural Hematoma}

- Indications for surgical intervention: i) Hematoma $\geq 1 \mathrm{~cm}$ in thickness. ii) Hematoma with a definite mass effect, or causing neurological deficit. iii) Rapidly progressing neurological deficit, even if the initial consciousness level was normal. iv) Surgery is usually not indicated if brainstem function is absent for a long time. Surgery performed as soon as possible is desirable.

- Methods: Large craniotomy with hematoma evacuation is the principle. In some cases, a burrhole or a small craniotomy is performed under local anesthesia, and decompression is attempted. A consensus has yet to be reached for external decompression, with reports for and against its efficacy.

\section{4-6. Intracerebral Hematoma, Brain Contusion}

- Indications: i) Presence of any of the following CT findings: hematoma (hyperdensity area) with a diameter of $3 \mathrm{~cm}$ or greater; diffuse contusion-induced edema; and disappearance of the basilar or perimesencephalic cisterns, etc. ii) Deterioration of neurological condition. iii) Uncontrollable increase in the ICP ( $\geq 30 \mathrm{mmHg}$ ): If the ICP is not monitored, decision is made according to criteria i) and ii) above. There is usually no indication for surgery if a long time has passed since the complete arrest of brainstem functions.

- Timing: i) If any of the criteria i)-iii) above are met, it is desirable to consider early surgery. ii) In patients with an initial GCS score of 9 or above, the early performance of surgery is desirable if the neurological condition is progressively deteriorating. iii) In patients with hematoma of the temporal or temporoparietal lobe, surgery may be considered before neurological deterioration.

- Methods: i) Hematoma evacuation by craniotomy is desirable. ii) If there is marked contusion-induced edema, contused brain tissue is often resected (internal decompression). iii) Indications of only extensive decompression craniotomy or in combination with hematoma removal and internal decompression may be evaluated. However, no consensus has been reached regarding the effectiveness of external decompression. iv) Continuous cerebrospinal fluid drainage (from the ventricles or cisterns) is also useful for the treatment of contusion-induced edema.

\section{4-7. Diffuse Brain Injuries}

Diffuse brain injuries such as those in patients remaining comatose immediately after injury despite the absence of a space-occupying lesion on CT should be treated conservatively, in principle.

\section{4-8. Traumatic Cerebrovascular Disorders}

Due to the development of noninvasive and rapid imaging modalities such as CT and MR imaging, instances of angiography performed in the initial stage of diagnosis and treatment of head injuries have become rare. This, however, has made the early diagnosis of head and neck vascular injuries more difficult. Traumatic cerebrovascular disorders are often accompanied by intracranial lesions and multiple injuries, and, if they are diagnosed, their treatment is often difficult.

\section{4-8-1. Tests for the diagnosis}

- Indications: Tests are indicated with conditions suggesting a strong possibility of the presence of traumatic cerebrovascular disorders as below are noted: i) If the neurological condition is difficult to explain based only on the TBI. ii) Delayed deterioration of clinical condition cannot be explained by the traumatic mechanism or the cerebral infarction detected by CT. iii) Thick, diffuse, severe subarachnoid hemorrhage or localized intense subarachnoid hemorrhage. iv) Neck injuries (fracture at or above the 5th cervical vertebra, fracture of the transverse 
process, hyperextension or hyperrotation of the neck, etc.). v) Cranial base fracture (fracture of the anterior cranial base reaching the medial 2/3 from the sphenoidal margin or the middle cranial base reaching the carotid canal). vi) Severe hemorrhage from the oral or nasal cavity or the external auditory meatus that is difficult to stop.

- Timing: If the above indications are met, diagnostic studies should be performed as soon as possible.

- Methods: MR anghiography or cerebral angiography is desirable. Cerebral angiography is considered to be the gold standard, because the cervical to intracranial blood vessels can be examined, and endovascular treatment can be immediately initiated. Although there are limitations concerning the diagnostic power, simple tests that can be performed at the bedside, such as cervical and transcranial Doppler sonography, may also be useful.

\section{4-8-2. Treatment}

- Indications: Treatment is indicated when bleeding (vascular rupture, arteriovenous fistula, traumatic aneurysm, etc.) or non-bleeding head and neck vascular lesions (wall irregularity, narrowing, obstruction, etc., of vessels) are detected by the studies.

- Timing: It is desirable to initiate treatment as soon as possible.

- Methods: i) Since life-threatening bleeding may occur from traumatic vascular lesions, early treatment should be considered. Direct surgery or endovascular treatment is selected depending on the situation, but their combination is often effective. In carotid-cavernous fistula, if massive nasal bleeding persists or if a large shunt induces a significant "steal" phenomenon, making the peripheral cerebral circulation unsatisfactory, it is desirable to attempt its closure as soon as possible by endovascular treatment. ii) In non-bleeding lesions, it is desirable to initiate heparin administration to prevent new cerebral infarction. However, if there is a possibility of intracranial hemorrhage or an increase in hemorrhage due to multiple injuries, administration is often started after stabilization of the condition. In the subacute period, administration of an antiplatelet agent should be considered.

\section{4-8-3. Comments}

Traumatic cerebrovascular disorders associated with neck injury are often obstructive and multiple or bilateral.

Cerebrovascular disorders may also occur during sports or chiropractics. Physical characteristics such as a flexible or long neck are considered to be risk factors for vascular disorders due to neck injuries.

Cerebrovascular disorders caused by shearing in- jury have been reported to be common in the peripheral part of the anterior cerebral artery or cervical vessels.

\section{4-9. Traumatic Cerebrospinal Fluid Leakage}

Traumatic cerebrospinal fluid leakage stops spontaneously within $1-3$ weeks in $50-80 \%$ of patients. Spontaneous healing of recurrent or delayed cases is rare. Even after spontaneous resolution, there is a risk of future recurrent cerebrospinal fluid leakage and complication by meningitis.

- Indications: i) Persistent cerebrospinal fluid leakage that cannot be stopped by conservative treatment in 1-3 weeks. ii) Recurrent or delayed cerebrospinal fluid leakage

- Timing: i) Surgery is generally performed after conservative treatment. ii) Surgery should be planned promptly for recurrent or delayed cases.

- Methods: i) Duraplasty (closure of the ruptured dura mater by suturing, repair of the ruptured dura mater using fascia or periosteum, etc.) is performed by craniotomy. It is often carried out starting intradurally. ii) There are also reports recommending transnasal endoscopic repair as the first choice.

\section{4-10. Fracture of the Optic Canal, Optic Nerve Injury}

Traumatic optic nerve injury may occur without fracture of the optic canal.

\section{4-10-1. Injury mechanisms}

Primary injury: Direct damage to the optic nerve per se (optic canal fracture).

Secondary injury: Delayed damage of the optic nerve due to circulation disorder or edema.

\section{4-10-2. Treatment}

Conservative treatment by drug therapy primarily using steroids.

Surgical treatment primarily by optic canal decompression.

- Indications: i) Surgery is often indicated for patients who have light perception preserved, clear evidence of fracture, and visual impairment. ii) Patients initially with only mild visual impairment are often treated surgically if they show fracture and progressive visual impairment. iii) Patients completely blind immediately after injury are usually considered to have no surgical indications.

- Timing: i) Very early surgery: Decision to perform surgery may be made after administering steroids and evaluating recovery after 48-72 hours. ii) Early surgery: Surgery within 1-2 weeks after injury is desirable. iii) Surgery 30 days or more after injury is ineffective and undesirable.

- Surgical procedure: Optic canal decompression 


\section{4-11. Anesthesia and Antibiotics}

4-11-1. Anesthesia

It is desirable to perform intubation for the induction of anesthesia under cricoid cartilage compression on assuming a full stomach.

Anesthesia is often maintained using a venous anesthetic, avoiding an inhalation anesthetic, which may increase the intracranial pressure.

In severely injured patients, the first priority is stabilization of hemodynamics, and exact observance of the usual required dose of the anesthetic is unnecessary.

To protect the brain, a barbiturate is often selected as the anesthetic.

If hypothermia (brain hypothermia) is started before surgery, it is desirable to maintain the low brain temperature (body temperature).

It is desirable to control intraoperatively the CPP at $60 \mathrm{mmHg}$ or above and the ICP at $20 \mathrm{mmHg}$ or below.

During the operation, it is desirable to perform fluid infusion using preparations not containing glucose and, if necessary, to avoid hyperglycemia by in- travenous insulin injections.

\section{4-11-2. Antibiotics}

Since patients with severe head injuries have markedly reduced biological defense abilities, i.e., are immunocompromised, it is desirable to perform routine administration of antibiotics from an early stage of treatment.

Antibiotic therapy may be empiric, specific, or prophylactic.

The Centers for Disease Control and Prevention guidelines recommend the use of 1st or 2nd generation cephalosporins as empiric therapy.

Since the risks of pneumonia associated with controlled respiration and septicemia due to catheterization are high, periodic culture tests are desirable.

Efforts to clarify the focus of infection, causative microorganism, and drug sensitivity and to initiate specific therapy as early as possible are necessary.

Non-critical continuation of use of 3rd or 4th generation cephalosporins often induces the appearance of resistant strains including methicillinresistant Staphylococcus aureus, and results in persistent infection.

\section{ChAPTER 5: MANAgEMENT OF CRANIOFACIAL INJURIES}

\section{5-1. Blow-out Fracture}

- Indications: Refractory diplopia and esthetically intolerable enophthalmos.

- Timing: i) Elective surgery (1-3 weeks after injury) is commonly performed. ii) Emergency surgery is necessary in patients exhibiting an oculo-cardiac reflex (hypotension, bradycardia, nausea, and dizziness due to the vagus reflex) (more often observed in young patients). iii) Acute-stage surgery is selected for patients in whom the eyes are completely immobilized in a downward position, exposing the white of the eye (called white-eyed blowout), those who show no eye movement on the forced traction test, those who exhibit enophthalmos immediately after injury, etc. iv) Surgery within 2 weeks after injury is recommended in patients exhibiting diplopia in the 1st ocular position, a positive forced traction test, constriction of the orbital contents on imaging studies and those with large fractures.

- Methods: i) Inferior wall orbitoplasty by the trans-inferior palpebral approach is usually selected. ii) Trans-maxillary sinus reduction and inferior orbital wall fixation has also been performed by the placement of a balloon catheter in the maxillary sinus.

\section{5-2. Maxillofacial Injuries}

\section{5-2-1. Zygomatic bone fracture}

5-2-1-1. Fracture of the zygomatic arch

- Indications: Lockjaw due to depression of the arch; skin depression at the zygomatic arch.

- Timing: Surgery should be performed early after injury. Adhesion becomes more severe in the chronic stage.

- Methods: Reduction of the zygomatic arch under the temporal fascia by employing Gillies' procedure is a common treatment. In comminuted fracture, etc., fixation using miniplates is performed by direct surgery.

\section{5-2-1-2. Fracture of the zygomatic body}

In zygomatic body fracture, the frontal process of the zygomatic bone, inferior orbital margin, zygomatic arch, and inferior zygomatic crest are fractured (tripod or tetrapod fracture), and the zygomatic bone is displaced.

- Indications: Displacement of the zygomatic body is expected to cause permanent facial deformity.

- Timing: Early surgery is desirable. Adhesions become significant 2 weeks or more after injury.

- Methods: The fracture line is exposed by incision of the area lateral to the eyebrow, vestibule of the mouth, lower eyelid, etc., and the zygomatic body is reduced and fixed. Rigid fixation using 
miniplates is often performed. In patients showing minor displacement, zygomatic bone fracture may be treated by Gillies' blind reduction.

\section{5-2-2. Mandibular fracture}

The objective of treatment is to restore occlusion effective for mastication and normal jaw movements. Intermaxillary fixation is usually performed. Treatment must not be performed only for fusion of the fractured bone.

- Indications: Edentulous mandible, large displacements due to fracture, multiple fractures, mandibulomaxillary fracture, open fracture, bone defects, etc., are indications for invasive treatment.

- Timing: Surgery should be performed early after injury. Reduction becomes difficult due to adhesions in the chronic stage.

- Methods: Depressed soft tissues are surgically removed, and fixation is performed using miniplates or wires. Usually, intermaxillary fixation is required.

5-2-3. Maxillar fracture

\section{5-2-3-1. Le Fort III fracture}

Le Fort III fracture involves the orbit, nasal bone and ethmoid bone, and is often accompanied by anterior cranial base fracture. Since the injury is also often complicated by brain injuries, it is treated as an old fracture in many patients.

- Indications: Le Fort III fracture is an indication for surgery in all patients except those with severe brain injuries.

- Timing: Surgery should be performed as soon as possible after injury. In old Le Fort III injury, additional techniques such as osteotomy may be necessary.

- Methods: After mobilization and reduction of the joint, reconstruction is performed in the occluded state by intermaxillary fixation, and bone fragments are then fixed using wires or miniplates.

\section{5-2-3-2. Le Fort I and II fractures}

These fractures are often accompanied by fractures of other facial bones. Le Fort II fracture may be accompanied by cerebrospinal fluid leakage as a result of cranial base fracture. These fractures are accompanied by diplopia, ocular depression, infraorbital nerve injury, etc., because of the orbital wall fracture. The objective of treatment is to restore the facial morphology and dental occlusion.

- Indications: Le Fort I or II fracture is an indication for surgery in all patients, in principle.

- Timing: Surgery early after injury is desirable.

- Methods: Le Fort I: A transverse incision is made in the vestibule of the mouth under intermaxillary fixation and bone fixation using wire or miniplates is performed at the margin of the pyriform aperture. Le Fort II: After performing incision at the root of the nose, inferior orbital margin, or vestibule of the mouth, or, if the fracture is complex, performing coronal incision (bifrontotemporal incision), intermaxillary fixation and bone fixation are performed similarly to Le Fort I surgical technique.

\section{Chapter 6: Management of Pediatric and Geriatric Patients}

\section{6-1. Severe TBI in Infants, Children, and Adoles- cents}

These guidelines address key issues relating to the management of severe TBI in pediatric patients with a GCS score of 3-8. Pediatric is defined as $<16$ years of age.

\section{6-1-1. Prehospital management}

The purpose of prehospital management is to avoid secondary brain injury as much as possible. i) Hypoxia and hypotension should be avoided if possible, and attempts should be made to correct them immediately. ii) Supplementary oxygen should be administered, securing airway to maintain ventilation. iii) Cervical spine should be protected to maintain its stability. iv) Complicated injury should be managed immediately, if possible.

Comments: Prehospital hypoxia has a statistically significant negative impact on outcome.

6-1-2. Transportation to a special facility

i) Pediatric patients with TBI should be transport- ed to an emergency facility, which has a neurosurgical service and a CT scanner available at all times. It should have a pediatric service, if possible. ii) TBI patients with GCS 9-13 should be directly transported to a facility, which has both a neurosurgical and a pediatric services. iii) Severe TBI patients with GCS 3-8 should be directly transported either to an emergency center or a facility which has both a neurosurgical and a pediatric services.

\section{6-1-3. Evaluation on admission}

i) Both hypoxia and hypotension are often to develop rapidly in a child during apnea, hypoventilation, and airway obstruction. ii) Paleness, inactivity, and/or tachycardia are often to be considered as clinical signs of shock. iii) Hypotension is often a late sign of shock, appearing after the above mentioned clinical signs. iv) Focal neurological deficit is rarely recognized even in patients with intracranial injury. v) Patients should be checked systematically, including the possibility of child abuse injury. Body tem- 
perature should be maintained.

\section{6-1-4. Primary care after admission}

i) Management of general condition should take precedence over everything else. ii) Primary care includes airway, ventilation, and circulation maintenance. Hypoxia and hypotension should be avoided if possible, and attempts should be made to correct it immediately. iii) Blood pressure should be monitored frequently. Timely fluid administration should be provided to maintain systolic blood pressure in the normal range. iv) Airway should be secured in patients with GCS $<9$, or with hypoventilation. Initial therapy with $100 \%$ oxygen is appropriate in the resuscitation phase of care. v) Cervical spine should be protected to maintain its stability.

Comments: i) Hypoxia is defined as apnea, cyanosis, $\mathrm{PaO}_{2}<60 \mathrm{mmHg}$, or oxygen saturation $<90 \%$. ii) Hypoventilation is defined as ineffective respiratory rate for age, shallow or irregular respirations, frequent periods of apnea, or registered hypercarbia. iii) Normal respiratory rate is $30-45 / \mathrm{min}$ in infant, $25 / \mathrm{min}$ in 3 years old, and $20 / \mathrm{min}$ over years old. iv) Lower limit of systolic blood pressure for age may be estimated by the formula: $70 \mathrm{mmHg}+(2 \times$ age in years). v) In children, hypotension is defined as systolic blood pressure below the fifth percentile for age or by clinical signs of shock. vi) In patients with clinical signs of shock, internal and spinal cord injury should be evaluated. vii) If peripheral vascular access is difficult, intraosseous infusion of fluids is indicated. viii) Bolus injection of lactate Ringer's solution $20 \mathrm{ml} / \mathrm{kg}$ should be provided immediately after diagnosis of shock. ix) Combination of hypotension and hypoxia increase morbidity and mortality.

\section{6-1-5. Management in intensive care unit}

Techniques and indications for ICP monitoring: i) ICP should be monitored in patients with severe TBI. ii) Ventricular catheter or catheter tip pressure transducer device is an accurate and reliable method of monitoring ICP. iii) ICP monitoring is not routinely indicated in patients with mild or moderate head injury. iv) ICP should be monitored in patients with severe TBI, who receive barbiturate therapy or hypothermia therapy.

Comments: i) A ventriculostomy catheter device also allows therapeutic cerebrospinal fluid drainage. ii) Parenchymal ICP monitoring with fiber optic or strain gauge catheter is reliable but has the potential for measurement drift. iii) ICP measurement data with parenchymal ICP catheter correlate well with those of a ventriculostomy catheter. iv) Overall safety of ICP monitoring devices is excellent, with clinically significant complications, such as infection, occurring infrequently. v) In infants, even with nor- mal CT findings, intracranial hypertension may be potentially present. vi) ICP monitoring and/or aggressive ICP control are associated with favorable outcome.

Threshold for treatment of intracranial hypertension: i) Treatment for intracranial hypertension, defined as pathologic elevation in ICP, should begin at ICP $\geq 15-20 \mathrm{mmHg}$. ii) Treatment of intracranial hypertension should be corroborated by monitoring data of physiological variables, such as ICP, CPP, $\mathrm{SjO}_{2}$, and cranial imaging.

CPP: i) In children with TBI, CPP $>40 \mathrm{mmHg}$ is desirable to be maintained. ii) CPP between 40 and $65 \mathrm{mmHg}$ probably represents an age-related continuum for the optimal treatment threshold.

Use of sedation and neuromuscular blockade: Sedatives, analgesics, and neuromuscular blocking agents are commonly used for emergency intubation, ICP control, mechanical ventilation, and cranial imaging. However, attention should be paid to unfavorable side effects, such as sedative-induced decrease in arterial blood pressure.

Comments: i) Bolus injection of ketamine is reported to decrease ICP in patients with severe TBI, but may raise ICP. ii) Neuromuscular blockade have been reported to reduce ICP, oxygen consumption, and energy consumption. iii) Propofol is not indicated for pediatric sedation as safety has not been established.

CSF drainage to manage ICP: CSF drainage can be considered as an option in the management of elevated ICP in children with severe closed head injury.

Comments: i) Drainage can be accomplished via only a ventriculostomy catheter or in combination with a lumbar drain. ii) Addition of lumbar drainage should be considered as an option only in the case of refractory intracranial hypertension with a functioning ventriculostomy, open basal cisterns, and no evidence of a major mass lesion or shift on imaging studies.

Use of hyperosmolar therapy: i) Both mannitol and glycerol may be effective for control of ICP after severe TBI. ii) Serum osmolarity should be maintained below $310 \mathrm{mOsm} / \mathrm{l}$ with mannitol use. iii) Effective bolus doses of mannitol range from 0.25 to $1.0 \mathrm{~g} / \mathrm{kg}$ of body weight. iv) Euvolemia should be maintained by fluid replacement.

Comments: i) Acute tubular necrosis and renal failure have been observed with mannitol administration with serum osmolarity levels $>320 \mathrm{mOsm} / \mathrm{l}$. Much higher levels of serum osmolarity (360 $\mathrm{mOsm} / \mathrm{l}$ ) appear to be well tolerated in children when induced with hypertonic saline. ii) Hypertonic saline is effective for control of increased ICP after 
severe TBI. iii) Effective doses as a continuous infusion of $3 \%$ saline range between 0.1 and 1.0 $\mathrm{ml} / \mathrm{kg} / \mathrm{hr}$.

Use of hyperventilation: i) Chronic prolonged hyperventilation therapy should be avoided. ii) Hyperventilation therapy $\left(\mathrm{PaCO}_{2}\right.$ of $\left.30-35 \mathrm{mmHg}\right)$ may be necessary for brief periods if there is acute neurological deterioration or for longer periods if there is intracranial hypertension refractory to sedation, paralysis, cerebrospinal fluid drainage, and osmotic diuretics. iii) $\mathrm{SjO}_{2}$, arterial jugular venous oxygen content differences, and ICP monitoring may help to identify cerebral ischemia if hyperventilation, resulting in $\mathrm{PaCO}_{2}$ values $<30 \mathrm{mmHg}$, is necessary. iv) Prophylactic hyperventilation therapy during the first 24 hours after severe TBI should be avoided because it can compromise cerebral perfusion during a time when CBF is reduced.

Comments: i) Hyperventilation induces hypocapnia, leading to cerebral vasoconstriction accompanied by a reduction in cerebral blood volume and a decrease in ICP. However, hyperventilation is associated with a risk of iatrogenic ischemia. ii) Cerebrovascular response to hyperventilation can be extremely variable following TBI. CBF, $\mathrm{SjO}_{2}$, or brain tissue oxygen monitoring may be suggested to help identify cerebral ischemia in this setting. iii) Mild or prophylactic hyperventilation $\left(\mathrm{PaCO}_{2}<35\right.$ $\mathrm{mmHg}$ ) in children should be avoided. iv) Aggressive hyperventilation $\left(\mathrm{PaCO}_{2}<30 \mathrm{mmHg}\right)$ may be considered as a second tier option in the setting of refractory intracranial hypertension.

Use of barbiturates in the control of intracranial hypertension: i) High-dose barbiturate therapy may be considered in hemodynamically stable patients with salvageable severe TBI and refractory intracranial hypertension. ii) If high-dose barbiturate therapy is used, appropriate hemodynamic monitoring and cardiovascular support are essential.

Comments: i) High-dose barbiturates are known to reduce ICP, but are also associated with increased risk of hypotension. ii) Monitoring of EEG patterns for burst suppression is thought to be reflective of therapeutic effect. iii) Therapeutic regimens (Nordby, 1984): protocol for thiopental: loading dose, $10-20 \mathrm{mg} / \mathrm{kg}$; maintenance, $3-5 \mathrm{mg} / \mathrm{kg} / \mathrm{hr}$. iv) Barbiturates are effective in lowering ICP in selected cases of refractory intracranial hypertension in children with severe TBI. However, studies on the effect of barbiturate therapy have not evaluated neurological outcome. v) Potential complications of high-dose barbiturate therapy in infants and children with severe TBI mandate that its use be limited. vi) There is no evidence to support use of barbiturates for prophylactic neuroprotective effects.
Temperature control following severe pediatric TBI: i) Hyperthermia should be avoided in children with severe TBI. ii) Hypothermia may be considered in the setting of refractory intracranial hypertension. iii) Appropriate hemodynamic monitoring may be required, as well as monitoring of ICP and $\mathrm{SjO}_{2}$.

Comments: Posttraumatic hyperthermia is defined as core body temperature $>38.5^{\circ} \mathrm{C}$.

Decompressive craniectomy: Decompressive craniectomy should be considered in pediatric patients with severe TBI, diffuse cerebral swelling, and intracranial hypertension refractory to intensive medical management.

Comments: i) Decompressive craniectomy is reported to significantly reduce mean ICP in children with severe TBI and has a trend toward better clinical outcome at 6 months after injury. ii) In patients who underwent bifrontal decompressive craniectomy for severe TBI, favorable outcome was more frequent in pediatric than adult patients. iii) As surgical techniques, unilateral fronto-temporoparietal craniectomy for unilateral cerebral swelling or bilateral frontal craniectomy for bilateral cerebral swelling have been generally recommended. iv) Decompressive craniectomy should be considered in the treatment of severe TBI and medically refractory intracranial hypertension in infants and young children with head trauma due to abuse. v) Decompressive craniectomy may be most appropriate in patients meeting some or all of the following criteria: diffuse cerebral swelling on cranial CT imaging, within 48 hours of injury, no episodes of sustained ICP $>40 \mathrm{mmHg}$ before surgery, GCS $>3$ at some point subsequent to injury, secondary clinical deterioration, and evolving cerebral herniation syndrome.

Use of corticosteroids: The use of steroids is undesirable for improving outcome or reducing ICP in pediatric patients with severe TBI.

Comments: i) Steroids are useful in reducing cerebral edema, attenuating free radical production in experimental models of TBI. ii) Corticosteroids did not improve functional outcome in adult patients with severe TBI. iii) Use of steroids significantly reduces endogenous cortisol production, and may have an associated increased risk of infection in children.

Nutritional support: i) Nutritional support should begin by 72 hours with full replacement by 7 days. ii) Replace $130-160 \%$ of resting metabolism expenditure after TBI in pediatric patients.

Comments: i) Mean energy expenditure is reported to be significantly elevated in pediatric as well as adult patients with severe TBI. ii) Serum glucose levels should be tightly controlled even in pediatric 
patients with severe TBI. iii) Based on the adult guidelines, weight-specific nutritional support should be provided in pediatric patients with TBI.

Anti-convulsive prophylaxis: i) Prophylactic anticonvulsant therapy may be considered as a treatment option to prevent early posttraumatic seizures (PTSs) in young pediatric patients and infants at high risk for seizures following head injury. ii) Prophylactic use of anti-convulsant therapy is not recommended for children with severe TBI for preventing late PTS.

Comments: i) Infants and small children are known to have lower seizure thresholds, leading to a greater risk of early PTS compared with adults after severe TBI. ii) In the acute period after severe TBI, seizures increase brain metabolic demands and ICP, and may lead to secondary brain injury resulting in unfavorable outcome. iii) PTSs are classified as early (occurring within 7 days) or late (occurring after 7 days) following injury. The reported incidence of early PTS after severe TBI in children varies from approximately $20-39 \%$. iv) Children $<2$ years of age have almost a three-fold greater risk of early PTS compared with older children up to 12 years of age. v) Majority of cases of early pediatric PTS occur within the first 24 hours after injury. vi) Among children $<3$ years old who had brain trauma and early PTS, $12 \%$ of infants and toddlers experienced late PTS, and risk of late PTS was significantly greater among children $<1$ year of age compared with 2 and 3-year-old children. vii) Phenytoin has been shown to reduce the incidence of early PTS in a single study of children with severe TBI. viii) Anticonvulsant therapy to prevent the occurrence of early PTS in high risk children during the first week following severe TBI is recommended as a treatment option.

Head elevation: i) The cranial part of the bed may be elevated to approximately $15-30^{\circ}$ to control ICP, and the response of ICP and CPP monitored for efficacy. ii) Cervical flexion should be avoided in pediatric patients with TBI to secure venous return.

Comments: i) Attention should be paid to instabil- ity of the head in pediatric patients with TBI, because of the relatively large cranium and short neck. ii) CPP should be monitored, if possible. iii) Head elevation $>30^{\circ}$ may result in a greater risk of decreased CPP in case of systemic hypotension.

\section{6-2. Severe Head Injury in the Elderly}

i) Main causes of severe traumatic brain injuries in aged group are pedestrian traffic accidents and falls in daily life. ii) Mortality rate increases with age. According to the JNTDB, the mortality rate in patients aged over 70 years is over $70 \%$ with or without surgical treatment. iii) Incidence of focal brain injuries such as acute subdural hematoma and brain contusion is higher and that of acute epidural hematoma is lower in the aged group. Higher incidence of multiple traumas is one of the poor prognostic factors in the aged group. iv) Intensive general care is desirable in the aged group, because systemic complications are major causes $(35-40 \%)$ of early death. v) Individuals aged 50 years and older are more likely to sustain progressive neurological deterioration into coma after suffering acute subdural hematoma, contusion hematoma, or intracerebral hematoma. GCS at deterioration, not initial GCS, has prognostic value. Early surgical intervention is indicated if patients deteriorate. Time between injury and deterioration is less than 3 hours in $80 \%$ of acute epidural or subdural hematoma patients, but is longer in brain contusion or intracerebral hematoma patients. vi) Surgical indications for acute subdural hematoma: Surgical intervention may not be indicated in patients with GCS 3 . With early and intensive treatment, patients with GCS 4 or more and independent before injury may have good prognosis even aged over 75 years. In patients with GCS 5 or less, hematoma irrigation with trephination therapy might be more effective than external decompression. vii) Recovery from higher cortical dysfunction after TBI takes longer in the aged group. Intensive treatment and care might be extended to the chronic phase in the elderly.

\section{Chapter 7: MANAgement OF Mild OR MOderate HeAd INJURIES -RISK FACTORS FOR DETERIORATION-}

7-1. Predictive Factors of Deterioration: Findings Suggestive of Organic Intracranial Injury (Tables 4 and 5)

Disturbance of consciousness, disorientation, amnesia, (a GCS score <15), or other neurological abnormalities noted on evaluation.

Presence of any of the following if there are none of the above findings: i) episode of loss of consciousness, amnesia, or disorientation after injury; ii) frequent vomiting or headache; iii) epileptic attack; iv) condition suggestive of depressed or cranial base fracture; v) head radiograph suggestive of fracture; vi) circumstances of injury suggestive of severe fracture (traffic accident, fall from a high place, etc.); vii) 
Table 4 Canadian Computed Tomography (CT) Head Rules for patients with minor head injury (adult)*

High risk (for neurological intervention)

GCS score $<15$ at 2 hrs after injury

Suspected open or depressed skull fracture

Any sign of basal skull fracture

Vomiting $\geq 2$ episodes

Age $\geq 65$ yrs

Medium risk (for brain injury on CT)

Amnesia before impact $>30 \mathrm{~min}$

Dangerous mechanism (pedestrian struck by motor vehicle, occupant ejected from motor vehicle, fall from height $>1 \mathrm{~m}$ or five stairs)

${ }^{*}$ Minor head injury is defined as witnessed loss of consciousness, definite amnesia, or witnessed disorientation in a patient with a Glasgow Coma Scale (GCS) score of 13-15.

old age; viii) condition suggestive of blood clotting abnormalities such as a regular use of warfarin; and ix) history of neurosurgical operation (ventriculoperitoneal shunt, etc.)

\section{7-2. Risk Factors of Deterioration}

Airway obstruction (hypoxemia, increased ICP).

Hypoxia and hypotension (exacerbation of brain edema, decrease in CPP).

Hyperglycemia.

Underestimation of the injury mechanism.

Overlooking of complicating injuries (cervical spinal injury, cardiac tamponade, hemopneumothorax, lung contusion, intraperitoneal hemorrhage, pelvic hemorrhage, etc.)

Delayed referral to an expert facility.

\section{7-3. Methods of Management}

Observation of the respiratory condition, chest auscultation.

Checking of vital signs and continuous observation.
Table 5 Request computed tomography (CT) immediately (National Institute for Health and Clinical Excellence head injury guidelines)

1. All patients with any of the following risk factors:

GCS $<13$

GCS 13 or 14 at 2 hrs after the injury

Suspected open or depressed fracture

Any sign of basal skull fracture

Posttraumatic seizure

Focal neurological deficit

More than one episode of vomiting (clinical judgment should be used regarding the cause of vomiting in patients aged $\leq 12 \mathrm{yrs}$ )

Amnesia $>30$ min of events before impact (assessment will not be possible in pre-verbal children and is unlikely to be possible in any child aged $<5 \mathrm{yrs}$ )

2. CT should also be requested immediately in the following situations provided the patient has experienced some loss of consciousness or amnesia since the injury: Age $\geq 65$ yrs

Dangerous mechanism of injury: pedestrian struck by a motor vehicle, occupant ejected from a motor vehicle or fall from a height of greater than $1 \mathrm{~m}$ or five stairs (a lower threshold for height of falls should be used when dealing with infants and young children aged $<5 \mathrm{yrs})$.

Coagulopathy

GCS: Glasgow Coma Scale.

Adjustment of the blood glucose level.

Evaluation of the injury mechanism (high-impact injury).

Initial evaluation by head and neck radiography. Initial diagnosis and serial follow-up by CT.

Early consultation with a neurosurgeon, etc.

\section{Acknowledgment}

We would like to thank Dr. Kostadin L. Karagiozov for his technical assistance.

\section{SELECTED REFERENCES}

In total 428 English and Japanese articles were reviewed, 203 English articles were selected for these references.

\section{Chapter 1: Emergency care system and neurosurgi- cal department (neurosurgeons)}

1) Sugiura K, Furuya R, Kunimoto K, Endoh S, Tachisawa T, Muraoka K: Significance of different levels of the Edinburgh 2 Coma Scale calculated from the outcome of neurosurgical patients. Neurosurgery 31:
1023-1029, 1992

\section{Chapter 3: ICU management}

1) Aibiki M, Maekawa S, Yokono S: Moderate hypothermia improves imbalances of thromboxane A2 and prostaglandin I2 production after traumatic brain injury in humans. Crit Care Med 28: 39023906, 2000

2) Albanèse J, Arnaud S, Rey M, Thomachot L, Alliez B, Martin C: Ketamine decreases intracranial pres- 
sure and electroencephalographic activity in traumatic brain injury patients during propofol sedation. Anesthesiology 87: 1328-1334, 1997

3) Alderson P, Roberts I: Corticosteroids in acute traumatic brain injury: systematic review of randomised controlled trials. BMJ 314: 1855-1859, 1997

4) American Association for the Surgery of Trauma; Child Neurology Society; International Society for Pediatric Neurosurgery; International Trauma Anesthesia and Critical Care Society; Society of Critical Care Medicine; World Federation of Pediatric Intensive and Critical Care Societies; National Center for Medical Rehabilitation Research; National Institute of Child Health and Human Development; National Institute of Neurological Disorders and Stroke; Synthes USA; International Brain Injury Association: Guidelines for the acute medical management of severe traumatic brain injury in infants, children, and adolescents. J Trauma 54(6 Suppl): S235-310, 2003

5) American Society for Parenteral and Enteral Nutrition: Guidelines for the use of parenteral and enteral nutrition in adults and pediatric patients. JPEN J Parenter Enteral Nutr 26 (1 Suppl): 1SA-138SA, 2002

6) Balestreri M, Czosnyka M, Steiner LA, Schmidt E, Smielewski P, Matta B, Pickard JD: Intracranial hypertension: what additional information can be derived from ICP waveform after head injury? Acta Neurochir (Wien) 146: 131-141, 2004

7) Bazarian JJ: Corticosteroids for traumatic brain injury. Ann Emerg Med 40: 515-517, 2002

8) Biswas AK, Bruce DA, Sklar FH, Bokovoy JL, Sommerauer JF: Treatment of acute traumatic brain injury in children with moderate hypothermia improves intracranial hypertension. Crit Care Med 30: 2742-2751, 2002

9) Borzotta AP, Pennings J, Papasadero B, Paxton J, Mardesic S, Borzotta R, Parrott A, Bledsoe F: Enteral versus parenteral nutrition after severe closed head injury. J Trauma 37: 459-468, 1994

10) Bourgoin A: Safety of sedation with ketamine in severe head injury patients: comparison with sufentanil. Crit Care Med 31: 711-717, 2003

11) Braakman R, Schouten HJ, Blaauw-van Dishoeck M, Minderhoud JM: Megadose steroids in severe head injury. Results of a prospective double-blind clinical trial. J Neurosurg 58: 326-330, 1983

12) Brawanski A, Faltermeier R, Rothoerl RD, Woertgen C: Comparison of near-infrared spectroscopyand tissue $\mathrm{PO}_{2}$ time series in patients after severe head injury and aneurysmal subarachnoid hemorrhage. J Cereb Blood Flow Metab 22: 605-611, 2002

13) Bruder N, Dumont JC, François G: Evolution of energy expenditure and nitrogen excretion in severe head-injured patients. Crit Care Med 19: 43-48, 1991

14) Bullock R, Chesnut RM, Clifton G, Chajar J, Marion DW, Narayan RK, Newell DW, Pitts LH, Rosner MJ,
Wilberger JE: Guidelines for the management of severe head injury. J Neurotrauma 13: 643-734, 1996

15) Burger R, Vince GH, Meixensberger J, Roosen K: Bilateral monitoring of $\mathrm{CBF}$ and tissue oxygen pressure in the penumbra of focal mass lesion in rats. Acta Neurochir Suppl 71: 157-161, 1998

16) Center for Drug Evaluation and Research. Available from: http://www.fda.gov/cder/pedtatric/labelchange.htm, accessed on May 5, 2003

17) Chambers IR, Treadwell L, Mendelow AD: Determination of threshold levels of cerebral perfusion pressure and intracranial pressure in severe head injury by using receiver-operating characteristic curves: an observational study in 291 patients. J Neurosurg 94: 412-416, 2001

18) Clifton GL, Miller ER, Choi SC, Levin HS, McCauley S, Smith KR Jr, Muizelaar JP, Wagner FC Jr, Marion DW, Luerssen TG, Chesnut RM, Schwartz M: Lack of effect of induction of hypothermia after acute brain injury. New Eng J Med 344: 556-563, 2001

19) Clifton GL, Robertson CS, Contant CF: Enternal hyperalimentation in head injury. J Neurosurg 62: 186-193, 1985

20) Clifton GL, Robertson CS, Grossman RG, Hodge S, Foltz R, Garza C: The metabolic response to severe head injury. J Neurosurg 60: 687-696, 1984

21) Coles JP, Minhas PS, Fryer TD, Smielewski P, Aigbirihio F, Donovan T, Downey SP, Williams G, Chatfield D, Matthews JC, Gupta AK, Carpenter TA, Clark JC, Pickard JD, Menon DK: Effect of hyperventilation on cerebral blood flow in traumatic head injury: clinical relevance and monitoring correlates. Crit Care Med 30: 1950-1959, 2002

22) Cooper PR, Moody S, Clark WK, Kirkpatrick J, Maravilla K, Gould AL, Drane W: Dexamethasone and severe head injury. A prospective double-blind study. J Neurosurg 64: 81-88, 1979

23) Cristofori L, Tavazzi B, Gambin R, Vagnozzi R, Vivenza C, Amorini AM, Di Pierro D, Fazzina G, Lazzarino G: Early onset of lipid peroxidation after human traumatic brain injury: a fatal limitation for the free radical scavenger pharmacological therapy? J Investig Med 49: 450-458, 2001

24) Cruz J: Adverse effects of pentobarbital on cerebral venous oxygenation of comatose patients with acute traumatic brain swelling: relationship on outcome. J Neurosurg 85: 758-761, 1996

25) Cruz J: The first decade of continuous monitoring of jugular bulb oxyhemoglobin saturation: management strategies and clinical outcome. Crit Care Med 26: 344-351, 1998

26) Czosnyka M, Czosnyka Z, Pickard JD: Laboratory testing of three intracranial pressure microtransducers: technical report. Neurosurgery 38: 219224, 1996

27) Czosnyka M, Pickard JD: Monitoring and interpretation of intracranial pressure. J Neurol Neurosurg Psychiatry 75: 813-821, 2004 
28) Czosnyka M, Smielewski P, Kirkpatrick P, Menon DK, Pickard JD: Monitoring of cerebral autoregulation in head-injured patients. Stroke 27: 1829-1834, 1996

29) Dearden NM, Gibson JS, McDowall DG, Gibson RM, Cameron MM: Effect of high-dose dexamethasone on outcome from severe head injury. J Neurosurg 64: 81-88, 1986

30) Doppenberg EM, Bullock R: Clinical neuroprotection trials in severe traumatic brain injury: lessons from previous studies. J Neurotrauma 14: 71-80, 1997

31) Edwards P, Arango M, Balica L, Cottingham R, ElSayed H, Farrell B, Fernandes J, Gogichaisvili T, Golden N, Hartzenberg B, Husain M, Ulloa MI, Jerbi Z, Khamis H, Komolafe E, Laloë V, Lomas G, Ludwig S, Mazairac G, Muñoz Sanchéz Mde L, Nasi L, Olldashi F, Plunkett P, Roberts I, Sandercock P, Shakur H, Soler C, Stocker R, Svoboda P, Trenkler S, Venkataramana NK, Wasserberg J, Yates D, Yutthakasemsunt S; CRASH trial collaborators: Final results of MRC CRASH, a randomised placebo-controlled trial of intravenous corticosteroid in adults with head injury-outcomes at 6 months. Lancet 365: 1957-1959, 2005

32) Eizenberg HM, Frankowski RF, Contant CF, Marshall LF, Walker MD: High-dose barbiturate control of elevated intracranial pressure in patients with severe head injury. J Neurosurg 69: 15-23, 1988

33) Fàbregas N, Gambús PL, Valero R, Carrero EJ, Salvador L, Zavala E, Ferrer E: Can bispectral index monitoring predict recovery of consciousness in patients with severe brain injury? Anesthesiology 101: 43-51, 2004

34) Feig PU, McCurdy DK: The hypertonic state. N Engl J Med 297: 1444-1454, 1977

35) Feldman Z, Kanter MJ, Robertson CS, Contant CF, Hayes C, Sheinberg MA, Villareal CA, Narayan RK, Grossman RG: Effect of head elevation on intracranial pressure, cerebral perfusion pressure, and cerebral blood flow in head-injured patients. J Neurosurg 76: 207-211, 1992

36) Firschung R, Woischneck D, Klein S, Reissberg S, Döhring W, Peters B: Classification of severe head injury based on magnetic resonance imaging. Acta Neurochir (Wien) 143: 263-271, 2001

37) Ghajar J, Hariri RJ, Narayan RK, Iacono LA, Firlik K, Patterson RH: Survey of critical care management of comatose, head-injured patients in the United States. Crit Care Med 23: 560-567, 1995

38) Giannotta SL, Weiss MH, Apuzzo ML, Martin E: High dose glucocorticoids in the management of severe head injury. Neurosurgery 15: 497-501, 1984

39) Glenn TC, Kelly DF, Boscardin WJ, McArthur DL, Vespa P, Oertel M, Hovda DA, Bergsneider M, Hillered L, Martin NA: Energy dysfunction as a predictor of outcome after moderate or severe head injury: indices of oxygen, glucose, and lactate metabolism. J Cereb Blood Flow Metab 23: 1239-
1250, 2003

40) Gopinath SP, Valadka AB, Uzura M, Robertson CS: Comparison of jugular venous oxygen saturation and brain tissue $\mathrm{PO}_{2}$ as monitors of cerebral ischemia after head injury. Crit Care Med 27: 2337-2345, 1999

41) Grahm TW, Zadrozny DB, Harrington T: The benefits of early jejunal hyperalimentation in the head injury. Neurosurgery 25: 729-735, 1989

42) Guerra WK: Surgical decompression for traumatic brain swelling: indication and results. J Neurosurg 90: 187-196, 1999

43) Gupta AK, Zygun DA, Johnston AJ, Steiner LA, AlRawi PG, Chatfield D, Shepherd E, Kirkpatrick PJ, Hutchinson PJ, Menon DK: Extracellular brain pH and outcome following severe traumatic brain injury. J Neurotrauma 21: 678-684, 2004

44) Harris OA, Colford JM Jr, Good MC, Matz PG: The role of hypothermia in the management of severe brain injury: a meta-analysis. Arch Neurol 59: 1077-1083, 2002

45) Hoelper BM, Reinert MM, Zauner A, Doppenberg $\mathrm{E}$, Bullock R: rCBF in hemorrhagic, non-hemorrhagic and mixed contusion after severe head injury and its effect on perilesional cerebral blood flow. Acta Neurochir Suppl 76: 21-25, 2000

46) Iwase $\mathrm{M}$, Takayama $\mathrm{N}$, Tanaka T, Kawamoto K: Clinical evaluation of nitric oxide and cytokines in patients with severe head injury. Neurosurgical Emergency 4: 27-33, 1999

47) James HE: Methodology for the control of intracranial pressure with hypertonic mannitol. Acta Neurochir (Wien) 51: 161-172, 1980

48) James HE, Langfitt TW, Kumar VS, Ghostine SY: Treatment of intracranial hypertension. Analysis of 105 consecutive, continuous recordings of intracranial pressre. Acta Neurochir (Wien) 36: 189-200, 1977

49) Jensen RL, Hahn YS, Ciro E: Risk factors on intracranial pressure monitoring in children with fiberoptic devices: a critical review. Surg Neurol 47: 16-22, 1997

50) Jiang J, Yu M, Zhu C: Effect of long-term mild hypothermia therapy in patients with severe traumatic brain injury: 1-Year follow-up review of 87 cases. J Neurosurg 93: 546-549, 2000

51) Juul N, Morris GF, Marshall SB, Marshall LF: Intracranial hypertension and cerebral perfusion pressure: influence on neurological deterioration and outcome in severe head injury. The Executive Committee of the International Selfotel Trial. J Neurosurg 92: 1-6, 2000

52) Kaufman AM, Cardoso ER: Aggravation of vasogenic cerebral edema by multi-dose mannitol. J Neurosurg 77: 584-589, 1992

53) Kaups KL, Davis JW, Parks SN: Routinely repeated computed tomography after blunt head trauma: does it benefit patients? J Trauma 56: 475-480, 2004

54) Khanna S, Davis D, Peterson B, Fisher B, Tung H, 
O’Quigley J, Deutsch R: Use of hypertonic saline in the treatment of severe refractory posttraumatic intracranial hypertension in pediatric traumatic brain injury. Crit Care Med 28: 1144-1151, 2000

55) Lam AM, Winn HR, Cullen BF, Sundling N: Hyperglycemia and neurological outcome in patients with head injury. J Neurosurg 75: 545-551, 1991

56) Lang EW, Chesnut RM: Intracranial pressure and cerebral perfusion pressure in severe head injury. New Horizons 3: 400-409, 1995

57) Lang EW, Lagopoulos J, Griffith J, Yip K, Mudaliar Y, Mehdorn HM, Dorsch NW: Noninvasive cerebrovascular autoregulation assessment in traumatic brain injury: validation and utility. J Neurotrauma 20: 69-75, 2003

58) Lannoo E, Colardyn F, De Deyne C, Vandekerckhove T, Jannes C, De Soete G: Cerebral perfusion pressure and intracranial pressure in relation to neuropsychological outcome. Intensive Care Med 24: 236-241, 1998

59) Lobato RD, Sarabia R, Cordobes F, Rivas JJ, Adrados A, Cabrera A, Gomez P, Madera A, Lamas E: Posttraumatic cerebral hemospheric swelling. Analysis of 55 cases studied with computed tomography. J Neurosurg 68: 417-422, 1988

60) Marmarou A, Fatouros PP, Barzó P, Portella G, Yoshihara M, Tsuji O, Yamamoto T, Laine F, Signoretti S, Ward JD, Bullock MR, Young HF: Contribution of edema and cerebral blood volume to traumatic brain swelling in head-injured patientsw. J Neurosurg 93: 183-193, 2000

61) Marshall LF, Marshall SB, Klauber MR, Van Berkum Clark M, Eisenberg HM, Jane JA, Lussen TG, Marmarou A, Foulkes MA: A new classification of head injury based on computed tomography. J Neurosurg 75 Suppl: S14-S20, 1991

62) Marshall LF, Marshall SB, Musch B, Means E: Outcome of moderate and severe head injury in patients treated with tirilazad mesylate. J Neurosurg 84: 342A (abstract), 1996

63) Matsumae $M$, Ishizaka $H$, Shiramizu $H$, Shibata $M$, Tsugane R: Pupillary abnormality on admission and brain bulging during surgery as unfavorable predictors in patients treated with hypothermia: a retrospective review of 81 patients with severe head injury. Acta Neuroshir 143: 1229-1235, 2001

64) Mazzini L, Pisano F, Zaccala M, Miscio G, Gareri F, Galante M: Somatosensory and motor evoked potentials at different stages of recovery from severe traumatic brain injury. Arch Phys Med Rehabil 80: 3339, 1999

65) McCall M, Jeejeebhoy K, Pencharz P, Moulton R: Effect of neuromuscular blockade on energy ependiture in patients with severe head injury. JPEN J Parenter Enteral Nutr 27: 27-35, 2003

66) McIntyre LA, Fergusson DA, Hébert PC, Moher D, Hutchison JS: Prolonged therapeutic hypothermia after traumatic brain injury in adults: a systematic review. JAMA 289: 2992-2999, 2003
67) McKinley BA, Parmley CL, Tonneson AS: Standardized management of intracranial pressure: a preliminary clinical trial. J Trauma 46: 271-279, 1999

68) Meixensberger J, Baunach S, Amschler J, Dings J, Roosen K: Influence of body position on tissue-PO2, cerebral perfusion pressure and intracranial pressure in patients with acute brain injury. Neurol Res 19: 249-253, 1997

69) Mendelow AD, Teasdale GM, Russell T, Flood J, Patterson J, Murray GD: Effect of mannitol on cerebral blood flow and cerebral perfusion pressure in human head injury. J Neurosurg 63: 43-48, 1985

70) Mittl RL, Grossman RI, Hiehle JF, Hurst RW, Kauder DR, Gennarelli TA, Alburger GW: Prevalence of MR evidence of diffuse axonal injury in patients with mild head injury and normal head CT findings. AJNR Am J Neuroradiol 15: 1583-1589, 1994

71) Moro-Sutherland DM, Algren JT, Louis PT, Kozinetz CA, Shook JE: Comparison of intravenous midazolam with pentobarbital for sedation for head computer tomography imaging. Acad Emerg Med 7: 1370-1375, 2000

72) Muizelaar JP, Marmarou A, Ward JD, Kontos HA, Choi SC, Becker DP, Gruemer H, Young HF: Adverse effects of prolonged hyperventilation in patients with severe head injury: a randomized clinical trial. J Neurosurg 75: 731-739, 1991

73) Münch E, Horn P, Schürer L, Piepgras A, Paul T, Schmiedek P: Management of severe traumatic brain injury by decompressive craniectomy. Neurosurgery 47: 315-323, 2000

74) Nordström CH, Messeter K, Sundbärg G, Schalén W, Werner M, Ryding E: Cerebral blood flow, vasoreactivity, and oxygen consumption during barbiturate therapy in severe traumatic brain lesions. J Neurosurg 68: 424-431, 1988

75) Ohata $\mathrm{H}$, Iida $\mathrm{H}$, Dohi $\mathrm{S}$, Watanabe $\mathrm{Y}$ : Intravenous dexmedetomidine inhibits cerebrovascular dilatation induced by isoflurane and sevoflurane in dogs. Anesth Analg 89: 370-377, 1999

76) Ott L, Annis K, Hatton J, McClain M, Young B: Postpyloric enteral feeding costs for patients with severe head injury: blind placement endoscopy, and PEG/J versus TPN. J Neurotrauma 16: 233-242, 1999

77) Pittman JE, Sheng H, Pearlstein R, Brinkhous A, Dexter F, Warner DS: Comparison of the effects of propofol and pentobarbital on neurologic outcome and cerebral infarct size after temporary ischemia in the rat. Anesthesiology 87: 1139-1144, 1997

78) Poon WS, Ng SC, Chan MT, Leung CH, Lam JM: Neurochemical changes in ventilated head-injured patients with cerebral perfusion pressure treatment failure. Acta Neurochir Suppl 81: 335-338, 2002

79) Pople IK, Muhlbauer MS, Sanford RA, Kirk E: Results and complications of intracranial pressure monitoring in 303 children. Pediatr Neurosurg 23: 64-67, 1995

80) Raabe A, Grolms C, Sorge O, Zimmermann M, 
Seifert V: Serum S-100B protein in severe head injury. Neurosurgery 45: 477-483, 1999

81) Rapp RP, Young B, Twyman D, Bivins BA, Haack D, Tibbs PA, Bean JR: The favorable effect of early parenteral feeding on survival in head-injured patients. J Neurosurg 58: 906-912, 1983

82) Raurich JM, Ibáñez J: Metabolic rate in severe head trauma. JPEN J Parenter Enteral Nutr 18: 521-524, 1994

83) Reinert M, Barth A, Rothen HU, Schaller B, Takala J, Seiler RW: Effects of cerebral perfusion pressure and increased fraction of inspired oxygen on brain tissue oxygen, lactate and glucose in patients with severe head injury. Acta Neurochir (Wien) 145: 341-349, 2003

84) Rhodes LK: Actions of glucocorticoids and related molecules after traumatic brain injury. Curr Opin Crit Care 9: 86-91, 2003

85) Roberts I, Yates D, Sandercock P, Farrell B, Wasserberg J, Lomas G, Cottingham R, Svoboda P, Brayley N, Mazairac G, Laloë V, Muñoz-Sánchez A, Arango M, Hartzenberg B, Khamis H, Yutthakasemsunt S, Komolafe E, Olldashi F, Yadav Y, Murillo-Cabezas F, Shakur H, Edwards P; CRASH trial collaborators: Effect of intravenous corticosteroids on death within 14 days in 10,008 adults with clinically significant head injury (MRC CRASH trial): randomized placebo-controlled trial. Lancet 364: 1321-1328, 2004

86) Robertson CS, Valadka AB, Hannay HJ, Contant CF, Gopinath SP, Cormio M, Uzura M, Grossman RG: Prevention of secondary ischemic insults after severe head injury. Crit Care Med 27: 2086-2095, 1999

87) Rosner MJ, Coley IB: Cerebral perfusion pressure, intracranial pressure, and head elevation. J Neurosurg 65: 636-641, 1986

88) Rovlias A, Kotsou S: The influence of hyperglycemia on neurological outcome in patients with severe head injury. Neurosurgery 46: 335-343, 2000

89) Sacks GS, Brown RO, Teaque D, Dickerson RN, Tolley EA, Kudsk KA: Early nutrition support modifies immune function in patients sustaining severe head injury. JPEN J Parenter Enteral Nutr 19: 387392, 1995

90) Sahuquillo J, Poca MA, Arribas M, Garnacho A, Rubio E: Interhemispheric supratentorial intracranial pressure gradients in head-injured patients: are they clinically important? J Neurosurg 90: 16-26, 1999

91) Sato M, Tanaka S, Suzuki K, Kohama A, Fujii C: Complications associated with barbiturate therapy. Resuscitation 17: 233-241, 1989

92) Saul TG, Ducker TB, Salcman M, Carro E: Steroid in severe head injury: a randomized clinical trial. J Neurosurg 54: 596-600, 1981

93) Schettini A, Stahurski B, Young HF: Osmotic and osmotic loop diuresis in brain surgery. Effects on plasma and CSF electrolytes and ion excretion. $J$ Neurosurg 56: 679-684, 1982

94) Schwartz ML, Tator CH, Rowed DW, Reid SR,
Meguro K, Andrews DF: The University of Toronto head injury treatment study: a prospective randomized comparison of pentobarbital and mannitol. Can J Neurol Sci 11: 434-440, 1984

95) Segatore M: Corticosteroids and traumatic brain injury: status at the end of the decade of the brain. $J$ Neurosci Nurs 31: 239-250, 1999

96) Servadei F, Nanni A, Nasi MT, Zappi D, Vergoni G, Giuliani G, Arista A: Evolving brain lesions in the first 12 hours after head injury: analysis of 37 comatose patients. Neurosurgery 37: 899-907, 1995

97) Shackford SR, Norton CH, Todd MM: Renal, cerebral and pulmonary effects of hypertonic resuscitation in a porcine model of hemorrhagic shock. Surgery 104: 553-560, 1988

98) Sheinberg M, Kanter MJ, Robertson CS, Contant CF, Narayan RK, Grossman RG: Continuous monitoring of jugular venous oxygen saturation in head-injured patients. J Neurosurg 76: 212-217, 1992

99) Shiogai T, Nagayama K, Damrinjap G, Saruta K, Hara M, Saito I: Morphological and hemodynamic evaluation by means of transcranial power Doppler imaging in patients with severe head injury. Acta Neurochir Suppl 71: 94-100, 1998

100) Shiogai T, Nara I, Saruta K, Hara M, Saito I: Continuous monitoring of cerebrospinal fluid acid-base balance and oxygen metabolism in patients with severe head injury: pathophysiology and treatments for cerebral acidosis and ischemia. Acta Neurochir Suppl 75: 49-55, 1999

101) Shiozaki T, Akai H, Taneda M, Hayakata T, Aoki M, Oda J, Tanaka H, Hiraide A, Shimazu T, Sugimoto $\mathrm{H}$ : Delayed hemispheric neuronal loss in severely head-injured patients. J Neurtotrauma 18: 665-674, 2001

102) Shiozaki T, Hayakata T, Taneda $M$, Nakajima $Y$, Hashiguchi N, Fujimi S, Nakamori Y, Tanaka H, Shimazu T, Sugimoto H: A multicenter prospective randomized controlled trial of the efficacy of mild hypothermia for severely head injury patients with low intracranial pressure. J Neurosurg 94: 50-54, 2001

103) Shiozaki T, Nakajima $Y$, Taneda M, Tasaki O, Inoue Y, Ikegawa H, Matsushima A, Tanaka H, Shimazu $\mathrm{T}$, Sugimoto H: Efficacy of moderate hypothermia in patients with severe head injury and intracranial hypertension refractory to mild hypothermia. J Neurosurg 99: 47-51, 2003

104) Shiozaki T, Sugimoto $H$, Taneda $M$, Yoshida $H$, Iwai A, Yoshioka T, Sugimoto T: Effect of mild hypothermia on uncontrollable intracranial hypotension after severe head injury. J Neurosurg 79: 363-368, 1993

105) Smith HP, Kelly DL Jr, McWhorter JM, Armstrong D, Johnson R, Transou C, Howard G: Comparison of mannitol regimens in patients with severe head injury undergoing intracranial monitoring. J Neurosurg 65: 820-824, 1986

106) Suchner U, Senftleben U, Eckart T, Scholz MR, 
Beck K, Murr R, Enzenbach R, Peter K: Enteral versus parenteral nutrition: effect on gastrointestinal function and metabolism. Nutrition 12: 13-22, 1996

107) Talke P, Bickler PE: Effects of dextmedetomidine on hypoxia-evoked glutamate release and glutamate receptor activity in hippocampal slices. Anesthesiology 85: 551-557, 1996

108) Taylor SJ, Fettes SB, Jewkes C, Nelson RJ: Prospective, randomized, controlled trial to determine the effect of early enhanced enteral nutrition on clinical outcome in mechanically ventilated patients suffering head injury. Crit Care Med 27: 2525-2531, 1999

109) Temkin NR, Dikmen SS, Wilensky AJ, Keihm J, Chabal S, Winn HR: A randomized, double-blind study of phenytoin for the prevention of post-traumatic seizures. N Engl J Med 323: 497-502, 1990

110) Tokutomi T, Morimoto K, Miyagi T, Yamaguchi S, Ishikawa K, Shigemori M: Optimal temperature for the management of severe traumatic brain injury: effect of hypothermia on intracranial pressure, systemic and intracranial hemodynamics, and metabolism. Neurosurgery 52: 102-112, 2003

111) Tornheim PA, McLaurin RL, Sawaya R: Effect of furosemide on experimental traumatic cerebral edema. Neurosurgery 4: 48-51, 1979

112) Unterberg AW, Kiening KL, Härtl R, Bardt T, Sarrafzadeh AS, Lanksch WR: Multimodal monitoring in patients with head injury: evaluation of the effects of treatment on cerebral oxygenation. J Trauma 42: S32-S37, 1997

113) Valadka AB, Goodman JC, Gopinath SP, Uzura M, Robertson CS: Compalison of brain tissue oxygen tension to microdialysis-based measures of cerebral ischemia in fatality head-injured humans. J Neurotrauma 15: 509-519, 1998

114) van Santbrink H, Schouten JW, Steyerberg EW, Avezaat CJ, Maas AI: Serial transcranial Doppler measurements in traumatic brain injury with special focus on the early posttraumatic period. Acta Neurochir (Wien) 144: 1141-1149, 2002

115) Vespa PM, Boscardin WJ, Hovda DA, McArthur DL, Nuwer MR, Martin NA, Nenov V, Glenn TC, Bergsneider M, Kelly DF, Becker DP: Early and persistent impaired percent alpha variability on continuous electroencephalography monitoring as predictive of poor outcome after traumatic brain injury. J Neurosurg 97: 84-92, 2002

116) Ward JD, Becker DP, Miller JD, Choi SC, Marmarou A, Wood C, Newlon PG, Keenan R: Failure of prophylactic barbiturate coma in the treatment of severe head injury. J Neurosurg 62: 383-388, 1985

117) Wardlaw JM, Stathasm PF: How often is haemosiderin not visible on routine MRI following traumatic intracerebral haemorrhage? Neuroradiology 42: 8184,2000

118) Winkelman C: Effect of backrest position on intracranial and cerebral perfusion pressures in traumatically brain-injured adults. Am J Crit Care 9: $373-380,2000$
119) Wintermark M, Chioléro R, van Melle G, Revelly JP, Porchet F, Regli L, Meuli R, Schnyder P, Maeder P: Relationship between brain perfusion computed tomography variables and cerebral perfusion pressure in severe head trauma patients. Crit Care Med 32: 1579-1587, 2004

120) Yokota H, Yamamoto $Y$, Naoe $Y$, Fuse A, Sato $H$, Unemoto K, Kurokawa A: Measurements of cortical cellular $\mathrm{pH}$ by intracranial tonometer in severe head injury. Crit Care Med 28: 3275-3280, 2000

121) Young B, Rapp RP, Norton JA, Haack D, Tibbs PA, Bean JR: Failure of prophylactically administered phenytoin to prevent late posttraumatic seizures. J Neurosurg 58: 236-241, 1983

122) Zhi D, Zhang S, Lin $X$ : Study on therapeutic mechanism and clinical effect of mild hypothermia in patients with severe head injury. Surg Neurol 59: 381-385, 2003

\section{Chapter 4: Surgical indications and procedures}

1) Aarabi B, Alden TD, Chesnut RM, Downs JH III, Ecklund JM, Eisenbereg HM, Farace E, Florin RE, Jane JA Jr, Krieger MD, Maas AIR, Nasrayan RK, Potapov AA, Salazar AM, Shaffrey ME, Walters BC: Management and prognosis of penetrating brain injury. $J$ Trauma 51: S3-S86, 2001

2) Albanese J, Leone M, Alliez JR, Kaya JM, Antonini F, Alliez B, Martin C: Decompressive craniectomy for severe traumatic brain injury: evaluation of the effects at one year. Crit Care Med 31: 2535-2538, 2003

3) Anand VK, Murali RK, Glasgold MJ: Surgical decision in the management of cerebrospinal fluid rhinorrhea. Rhinology 33: 212-218, 1995

4) Andrews BT, Chiles BW 3rd, Olsen WL, Pitts LH: The effects of intracerebral hematoma location on the risk of brain-stem compression and on clinical outcome. J Neurosurg 69: 518-522, 1988

5) Barkwer FG 2nd: Efficacy of prophylactic antibiotics for craniotomy: a meta-analysis. Neurosurgery 35: 484-492, 1994

6) Biffl WL, Moore EE, Elliott JP, Brega KE, Burch JM: Blunt cerebrovascular injuries. Curr Probl Surg 36: 505-599, 1999

7) Bok AP, Peter JC: Carotid and vertebral artery occlusion after blunt cervical injury: the role of MR angiography in early diagnosis. J Trauma 40: 986-972, 1986

8) Brodie HA: Prophylactic antibiotics for posttraumatic cerebrospinal fluid fistulae. A meta-analysis. Arch Otolaryngol Head Neck Surg 123: 749-752, 1997

9) Bula WI, Loes DJ: Trauma to the cerebrovascular system. Neuroimaging Clin N Am 4: 753-772, 1994

10) Bullock R, Golek J, Blake G: Traumatic intracerebral hematoma-which patients should undergo surgical evacuation? CT scan features and ICP monitoring as a basis for decision making. Surg Neurol 32: 181-187, 1989

11) Centers for Disease Control and Prevention: Guidelines for prevention of surgical site infection. Bull 
Am Coll Surg 85: 23-29, 2000

12) Friedman JA, Ebersold MJ, Quast LM: Post-traumatic cerebrospinal fluid leakage. World J Surg 25: 10621066, 2001

13) Gallbraith S, Teasdale G: Predicting the need for operation in the patient with an occult traumatic intracranial hematoma. J Neurosurg 55: 75-81, 1981

14) Guerra WK, Gaab MR, Dietz H, Muelkler JU, Piek J, Fritsch MJ: Surgical decompression for traumatic brain swelling: indications and results. J Neurosurg 90: 187-196, 1999

15) Guyot LL, Kazmierczak CD, Diaz FG: Vascular injury in neurotrauma. Neurol Res 23: 291-296, 2001

16) Ishikawa E, Meguro K, Yanaka K, Murakami T, Narushima K, Aoki T, Nose T: Intracerebellar penetrating injury and abscess due to a wooden foreign body-case report. Neurol Med Chir (Tokyo) 40: 458-462, 2000

17) Ito M, Sonokawa T, Mishina H, Sato K: Penetrating injury of the brain by the burr of a high-speed air drill during craniotomy: case report. J Clin Neurosci 8: 261-263, 2001

18) Jamieson KG, Yelland JD: Surgically treated traumatic subdural hematomas. J Neurosurg 37: 137-149, 1972

19) Kitakami A, Kirikae M, Kuroda K, Ogawa A: Transorbital-transpetrosal penetrating cerebellar injury-case report. Neurol Med Chir (Tokyo) 39: 150-152, 1999

20) Lobato RD, Rivas JJ, Gomez PA, Castañeda M, Cañizal JM, Sarabia R, Cabrera A, Muñoz MJ: Headinjured patients who talk and deteriorate into coma. Analysis of 212 cases studied with computerized tomography. J Neurosurg 75: 256-261, 1991

21) McGurt WF Jr, Stool SE: Cerebrospinal fistula: the identification and management in pediatric temporal bone fractures. Laryngoscope 105: 359-364, 1995

22) Meier U, Gräwe A: The importance of decompressive craniectomy for the management of severe head injuries. Acta Neurochir Suppl 86: 367-371, 2003

23) Mendizabal GR, Moreno BC, Flores CC: Cerebrospinal fluid fistula: frequency in head injuries. Rev Laryngol Otol Rhinol (Bord) 113: 423-425, 1992

24) Mine S, Yamakami I, Yamaura A, Hanawa K, Ikejiri M, Mizota A, Adachi-Usami E: Outcome of traumatic optic neuropathy: comparison between surgical and nonsurgical treatment. Acta Neurochir (Wien) 141: 27-30, 1999

25) Münch E, Horn P, Schürer L, Piepgras A, Paul T, Schmiedek P: Management of severe traumatic brain injury by decompressive craniectomy. Neurosurgery 47: 315-323, 2000

26) New PF, Aronow S: Attenuation measurements of whole blood and blood fractions in computed tomography. Radiology 121: 635-640, 1976

27) Ng M, Maceri DR, Levy MM, Crockett DM: Extracranial repair of pediatric traumatic cerebrospinal fluid rhinorrhea. Arch Otolaryngol Head Neck Surg 124: 1125-1130, 1998
28) Otsuka S, Nakatsu S, Matsumoto S, Sato S, Motozaki T, Ban S, Yamamoto T: Study on cases with posterior fossa epidural hematoma. Clinical feature and indication for operation. Neurol Med Chir (Tokyo) 30: 24-28, 1990

29) Polin RS, Shaffrey ME, Bogaev CA, Tisdale N, Germanson T, Bocchicchio B, Jane JA: Decompressive bifrontal craniectomy in the treatment of severe refractory posttraumatic cerebral edema. Neurosurgery 41: 84-94, 1997

30) Schneider GH, Bardt T, Lanksch WR, Unterberg A: Decompressive craniectomy following traumatic brain injury: ICP, CPP and neurological outcome. Acta Neurochir Suppl 81: 77-79, 2002

31) Seelig JM, Greenberg RP, Becker DP, Miller JD, Choi SC: Reversible brain-stem dysfunction following acute traumatic subdural hematoma: a clinical and electrophysiological study. J Neurosurg 55: 516-523, 1981

32) Sethi DS, Chan C, Pillay PK: Endoscopic management of cerebrospinal fluid fistulae and traumatic cephalocele. Ann Acad Med Singapore 25: 724-727, 1996

33) Spoor TC, Hartel WC, Lensink DB, Wilkinson MJ: Treatment of traumatic optic neuropathy with corticosteroids. Am J Ophthalmol 110: 665-669, 1990

34) Takanashi Y, Shinonaga M, Manaka H: Penetrating brain injury with nasal entry by a plastic stick. Case report. J Neurosurg Sci 46: 25-27, 2002

35) Villalobos T, Arango C, Kubilis P, Rathore M: Antibiotic prophylaxis after basilar skull fractures: a meta-analysis. Clin Infect Dis 27: 364-369, 1998

36) Whitefield PC, Patel H, Hutchinson PJ, Czosnyka M, Parry D, Menon D, Pickard JD, Kirkpatrick PJ: Bifrontal decompressive craniectomy in the management of posttraumatic intracranial hypertension. Br J Neurosurg 15: 500-507, 2001

37) Zafonte RD, Wood DL, Harrison-Felix CL, Valena NV, Black K: Penetrating head injury: a prospective study of outcomes. Neurol Res 23: 219-226, 2001

38) Zimmerman RA, Bilaniuk LT: Computed tomographic staging of traumatic epidural bleeding. Radiology 144: 809-812, 1982

Chapter 5: Management of craniofacial injuries

1) Alexander J: Oral and maxillofacial trauma: triage to definitive care, in Becker DP , Gudeman SK (eds): Text Book of Head Injury. Philadelphia, WB Saunders, 1989, pp 350-366

2) Burnstine MA: Clinical recommendations for repair od isolated orbital floor fractures: an evidence-based analysis. Ophthalmology 109: 1207-1211, 2002

3) Sires BS, Stanley RB Jr, Levine LM: Oculocardiac reflex caused by orbital floor trapdoor fracture: an indication for urgent repair. Arch Ophthalmol 116: 955-956, 1998

4) Vriens JP, Moos KF: Morbidity of the infraorbital nerve following orbitozygomatic complex fractures. J Craniomaxillofac Surg 23: 363-368, 1995 
5) Zachariades N, Papavassiliou D, Papademetriou I: The alterations in sensitivity of the infraorbital nerve following fractures of zygomaticomaxillary complex. J Craniomaxillofac Surg 18: 315-318, 1990

\section{Chapter 6: Management of pediatric and geriatric patients}

1) Albanese J: Ketamine decreases intracranial pressure and electroencephalographic activity in traumatic brain injury patients during propofol sedation. Anesthesiology 87: 1328-1334, 1997

2) Baldwin HZ, Rekate HL: Preliminary experience with controlled external lumbar drainage in diffuse pediatric head injury. Pediatr Neurosurg 17: 115-120, 1991

3) Carney NA, Chesnut R, Kochanek PM; American Association for Surgery of Trauma; Child Neurology Society; International Society for Pediatric Neurosurgery; International Trauma Anesthesia and Critical Care Society; Society of Critical Care Medicine; World Federation of Pediatric Intensive and Critical Care Societies: Guidelines for the acute medical management of severe traumatic brain injury in infants, children and adolescents. Pediatr Crit Care Med 4 (3 Suppl): S1, 2003

4) Center for Drug Evaluation and Research. Available from: http://www.gov/cder/pediatric/labelchange.htm, accessed on May 5, 2003

5) Chambers IR, Treadwell L, Mendelow AD: Deteremination of threshold levels of cerebral perfusion pressure and intracranial pressure in severe head injury by using receiver-operating characterristic curves: an observational study in 291 patients. J Neurosurg 94: 412-416, 2001

6) Cho DY, Wang YC, Chi CS: Decompressive craniectomy for acute shaken/impact baby syndrome. Pediatr Neurosurg 23: 192-198, 1995

7) Cooper PR, Moody S, Clark WK, Kirkpatrick J, Maravilla K, Gould AL, Drane W: Dexamethasone and severe head injury. J Neurosurg 51: 307-316, 1979

8) Downard C, Hulka F, Mullins RJ, Piatt J, Chesnut R, Quint P, Mann NC: Relationship of cerebral perfusion pressure and survival in pediatric brain-injured patients. J Trauma 49: 654-659, 2000

9) Fanconi S, Klöti J, Meuli M, Zaugg H, Zachmann M: Dexamethasone therapy and endogeneous coritsol production in severe pediatric head injury. Intensive Care Med 14: 163-166, 1988

10) Figaji AA, Fieggen AG, Peter JC: Early decompressive craniectomy in children with severe traumatic brain injury. Childs Nerv Syst 19: 666-673, 2003

11) Gruszkiewicz J, Doron Y, Peyser E: Recovery from severe craniocerebral injury with brain stem lesions in childhood. Surg Neurol 1: 197-201, 1973

12) James HE: Methodology for the control of intracranial pressure with hypertonic mannitol. Acta Neurochir (Wien) 51: 161-172, 1980

13) Kasoff SS, Lansen TA, Holder D, Filippo JS: Aggressive physilogic monitoring of pediatric trauma patients with elevated intracranial pressure. Pediatr Neurosci 14: 241-249, 1988

14) Khanna S, Davis D, Peterson B, Fisher B, Tung H, O'Quigley J, Deutsch R: Use of hypertonic saline in the treatment of severe refractory posttraumatic intracranial hypertension in pediatric traumatic brain injury. Crit Care Med 28: 1144-1151, 2000

15) Levy DI, Rekate HL, Cherny WB, Manwaring K, Moss SD, Baldwin HZ: Controlled lumbar drainage in pediatric head injury. J Neurosurg 83: 453-460, 1995

16) Lewis RJ, Yee L, Inkelis SH, Gilmore D: Clinical predictors of posttraumatic seizures in children with head trauma. Ann Emerg Med 22: 1114-1118, 1993

17) Miller JD, Piper IR, Dearden NM: Management of intracranial hypertension in head injury: matching treatment with cause. Acta Neurochir Suppl (Wien) 57: 152-159, 1993

18) Moore R, Najarian MP, Konvolinka CW: Measured energy expenditure in severe head trauma. J Trauma 29: 1633-1636, 1989

19) Nirula R, Gentilello LM: Futility of resuscitation criteria for the "young" and the "old" old trauma patient: a national trauma data bank analysis. J Trauma 57: 37-41, 2004

20) Nordby HK, Nesbakken R: The effect of high dose barbiturate decompression after severe head injury. A controlled clinical trial. Acta Neurochir (Wien) 72: 157-166, 1984

21) Peterson B, Khanna S, Fisher B, Marshall L: Prolonged hypernatremia controls elevated intracranial pressure in brain-injured pediatric patients. Crit Care Med 28: 1136-1143, 2000

22) Pittman T, Bucholz R, Williams D: Efficacy of barbiturates in the treatment of resistant intracranial hyprertension in severely head injured children. Pediatr Neurosci 15: 13-17, 1988

23) Polin RS, Shaffrey ME, Bogaev CA, Tisdale N, Germanson T, Bocchicchio B, Jane JA: Dcompressive bifrontal craniectomy in the treatment of severe refractory posttraumatic cerebral edema. Neurosurgery 41: 84-94, 1997

24) Prabhakaran P, Reddy AT, Oakes WJ, King WD, Winkler MK, Givens TG: A pilot trial comparing cerebral perfusion pressure. Targeted therapy to intracranial pressure-targeted therapy in children with severe traumatic brain injury. J Neurosurg 100 (5 Suppl Pediatrics): 454-459, 2004

25) Shapiro K, Marmarou A: Clinical applications of the pressure-volume index in treatment of pediatric head injuries. J Neurosurg 56: 819-825, 1982

26) Shore PM, Thomas NJ, Clark RS, Adelson PD, Wisniewski SR, Janesko KL, Bayir H, Jackson EK, Kochanek PM: Continuous versus intermittent cerebrospinal fluid drainage after severe traumatic brain injury in children: effect on biochemical markers. J Neurotrauma 21: 1113-1122, 2004

27) Sires BS, Stanley RB Jr, Levine LM: Oculocardiac reflex caused by orbital floor trapdoor fracture: an in- 
dication for urgent repair. Arch Ophthalmol 116: 955-956, 1998

28) Skippen P, Seear M, Poskitt K, Kestle J, Cochrane D, Annich G, Handel J: Effect of hyperventilation on regional cerebral blood flow in head-injured children. Crit Care Med 25: 1402-1409, 1997

29) Stringer WA, Hasso AN, Thompson JR, Hinshaw DB, Jordan KG: Hyperventilation-induced cerebral ischemia in patients with acute brain lesions: demonstration by xenon-enhanced CT. AINR Am J Neuroradiol 14: 475-484, 1993

30) Taylor A, Butt W, Rosenfeld J, Shann F, Ditchfield M, Lewis E, Klug G, Wallace D, Henning R, Tibballs J: A randomized trial of very early decompressive craniectomy in children with traumatic brain injury and sustained intracranial hypertension. Childs Nerv Cyst 17: 154-162, 2001

31) Tilford JM, Simpson PM, Yeh TS, Lensing S, Aitken ME, Green JW, Harr J, Fiser DH: Variation in therapy and outcome for pediatric head trauma patients. Crit Care Med 29: 1056-1061, 2001

32) Vernon DD, Witte MK: Effect of neuromuscular blockade on oxygen consumption and energy expenditure in sedation, mechanically ventilated children. Crit Care Med 28: 1569-1571, 2000

33) Zweinenberg M: Severe pediatric head injury: the role of hyperemia revisited. J Neurotrauma 16: 937-943, 1999
Chapter 7: Management of mild and moderate head injuries - Risk factors for deterioration-

1) Ibañez J, Arikan F, Pedraza S, Sánchez E, Poca MA, Rodriguez D, Rubio E: Reliability of clinical guidelines in detection of patients at risk following mild head injury: results of a prospective study. J Neurosurg 100: 825-834, 2004

2) Korinthenberg R, Schreck J, Weser J, Lehmkuhl G: Post-traumatic syndrome after mild head injury cannot be predicted by neurological investigations. Brain Dev 26: 113-117, 2004

3) National Collaborate Centre for Acute Care: NICE Clinical Guidelines CG56: Head injury: triage, assessment, investigation and early management of head injury in infants, children and adults. National Institute for Health and Clinical Excellence, 2003. Available from: http://guideline.nice.org.uk/CG56

4) Servadei F, Teasdale G, Merry G; Neurotraumatology Committee of the World Federation of Neurosurgical Societies: Defining acute mild head injury in adults: a proposal based on prognostic factors, diagnosis, and management. J Neurotrauma 18: 657-664, 2001

5) Stiell IG, Wells GA, Vandemheen K, Clement C, Lesiuk H, Laupacis A, McKnight RD, Verbeek R, Brison R, Cass D, Eisenhauer ME, Greenberg G, Worthington J: The Canadian CT Head Rule for patients with minor head injury. Lancet 357: 1391-1396, 2001 